\title{
African American women's use of cosmetics products in relation to their attitudes and self-identity
}

by

\section{LaPorchia C. Davis}

\begin{abstract}
A thesis submitted to the graduate faculty
in partial fulfillment of the requirements for the degree of

MASTER OF SCIENCE
\end{abstract}
Major: Apparel, Merchandising, and Design
Program of Study Committee:
Mary Lynn Damhorst, Major Professor
Telin Chung
Zlatan Krizan

Iowa State University

Ames, Iowa

2013

Copyright @ LaPorchia C. Davis, 2013. All rights reserved. 


\section{DEDICATION}

This thesis is dedicated to my mother who has always supported me. 


\section{TABLE OF CONTENTS}

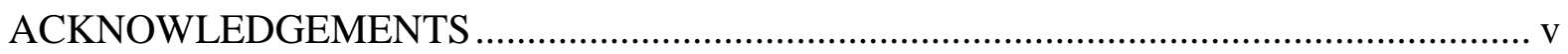

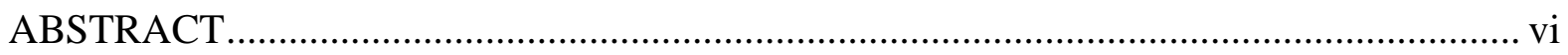

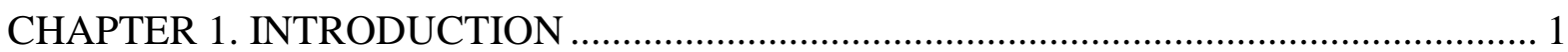

Issues of African American Women....................................................................... 4

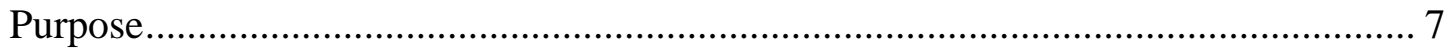

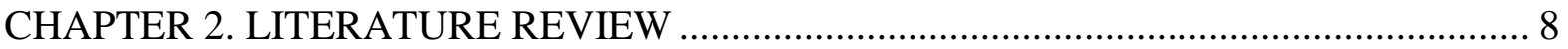

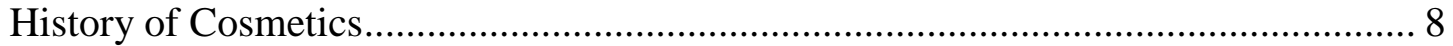

African American Cosmetics.................................................................... 9

Brand Loyalty and African Americans ..................................................................... 11

Media and Ideal Beauty Socialization …………………......................................... 13

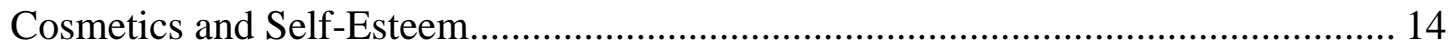

Cosmetics and Success ...................................................................................... 16

Cosmetic Surgery and Non-surgical Cosmetic Technologies .................................... 18

Potential Theoretical Foundations ........................................................................ 19

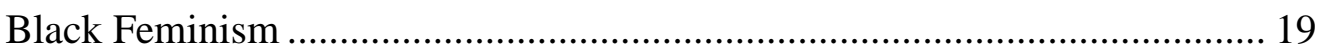

Social Comparison Theory …………………………………………….... 20

Symbolic Self-Completion Theory ............................................................ 22

Looking Glass Self, Self-Concept, and Identity …………………………..... 23

Self-Objectification ..................................................................................... 25

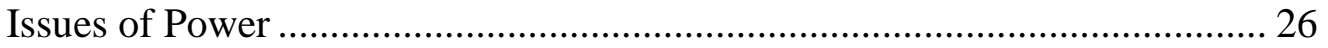

Research Questions ……………………………………………………………... 27

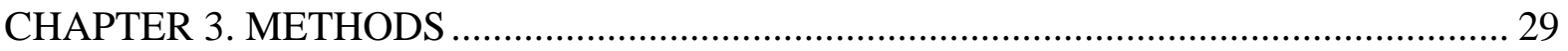

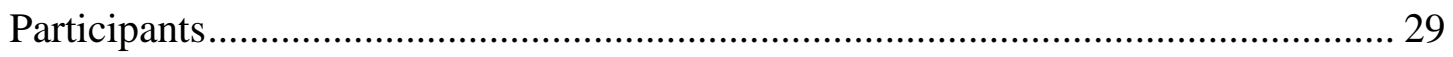

Sample

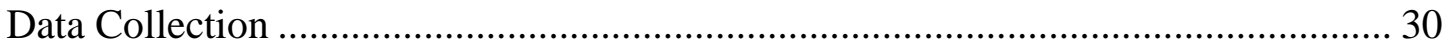

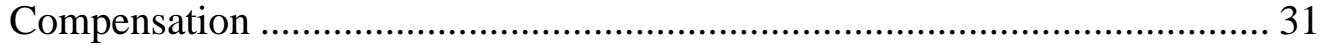

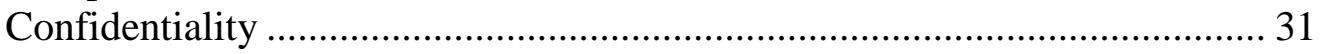

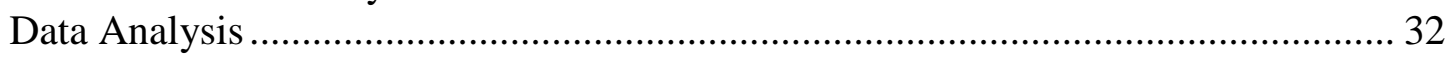

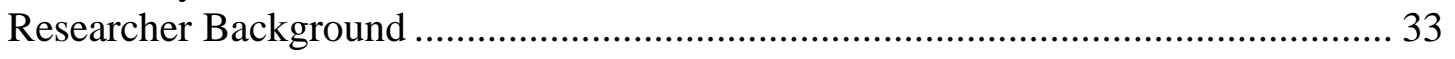

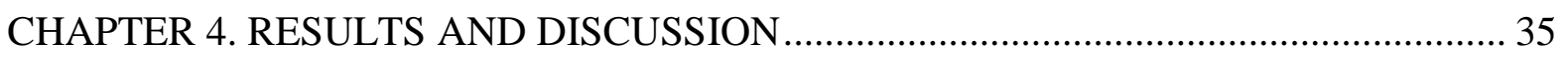

Overview of Participants..................................................................................... 35

Thematic Analysis Among Major Topic Findings ................................................... 37

Memories of First Use and Early Experiences ............................................... 38

Shopping Experience …………………………………........................... 42

Self-Enhancement …………………………………............................ 48

Brand Preference................................................................................... 54

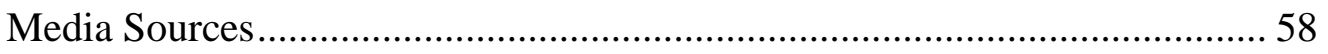

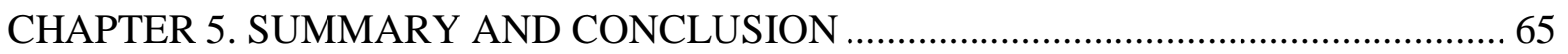




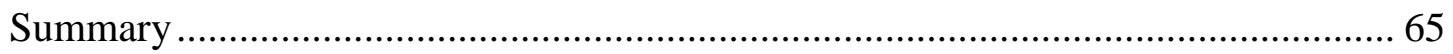

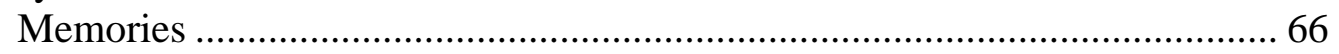

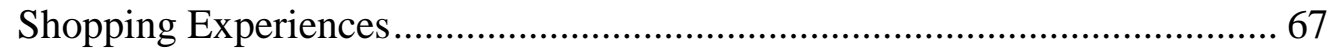

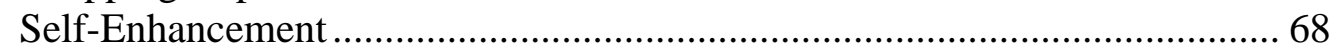

Brand Preference ................................................................................. 70

Media Sources................................................................................... 72

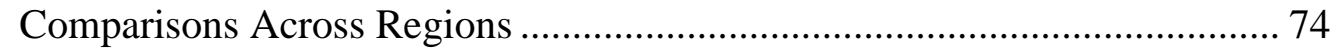

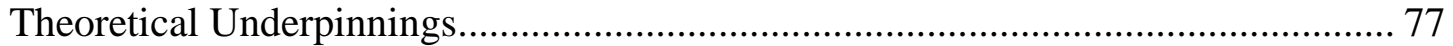

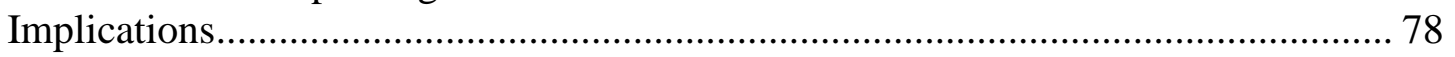

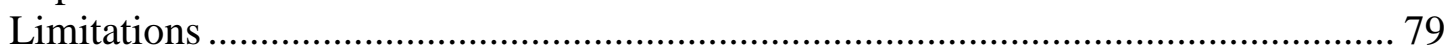

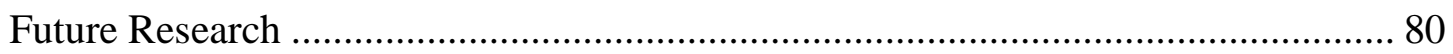

APPENDIX A. STUDY PARTICIPATION FLYER ................................................. 82

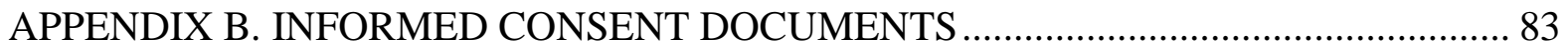

APPENDIX C. DEMOGRAPHIC QUESTIONNAIRE.............................................. 87

APPENDIX D. INTERVIEW QUESTIONS ............................................................ 88

APPENDIX E. INSTITUTIONAL REVIEW BOARD APPROVAL .............................. 89

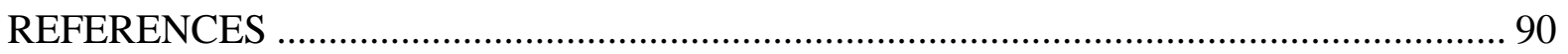




\section{ACKNOWLEDGEMENTS}

I would like to thank my mother for her support and encouraging words during this

endeavor. I would like to thank my advisor Dr. Mary Lynn Damhorst; I am so thankful to have you as my advisor and grateful for your guidance during this phase of my thesis research. I also want to thank my committee members Dr. Chung and Dr. Krizan for the advice and suggestions throughout my quest of completion. Furthermore, I would like to thank all of the women that participated in my research. Thank you. 


\begin{abstract}
The purpose of this study is to explore African American women's attitudes toward cosmetics, how women use cosmetics, and how use of the products is related to African American women's self-identity and self-perception of appearance. The sample was 18 African American women who were residents of Pine Bluff, Arkansas, or Ames, Iowa. Recruitment was done by placing announcements about the study on the university Minority Students Office and Southeast Arkansas African American professional listserve. In-depth interviews were conducted with each woman.

The women began wearing cosmetics at different periods in their lives during childhood, or adolescence. Shopping for cosmetics could be a hassle for some participants. Some reported difficulties in finding the right foundation to match their skin complexion. Many participants believed that finding cosmetics was a hit-or-miss experience when it came to shopping for cheaper cosmetics in local stores. Working with a consultant at a department store counter improved the experience. Stores in the predominantly White Iowa location carried few cosmetics appropriate for African American women's skin colors, causing much frustration on the part of the respondents in that location. Many of the women spent more money on quality cosmetics products that they felt made them look better and caused fewer skin problems. Many of the participants preferred the same brand of higher-end cosmetics. The women actively searched for YouTube tutorials to learn new tricks and techniques on how to apply their cosmetics.
\end{abstract}

For many of the women, wearing cosmetics is a form of "magic" that enhanced their beauty and self-confidence. Many of the women explained that applying cosmetics was needed to enhance their features; for a few, makeup was seen as unnecessary, but a nice 
addition. All used cosmetics to present an idealized appearance and enjoyed wearing them. The women in Arkansas made greater use of cosmetics on a daily basis, perhaps because of their work versus student roles and location in a larger African American community.

Social comparison, self-objectification, and symbolic self-completion theories were useful in interpreting the findings. Black feminist perspectives considering personal power and issues of inclusion and exclusion in media and retail settings were also incorporated in the analysis. 


\section{CHAPTER 1. INTRODUCTION}

According to the cosmetics industry, cosmetics play a huge role in and are an essential part of what many women consider important about their outward appearance. Many women feel inadequate in terms of their self-esteem and self-confidence, which can affect their evaluation of personal beauty (Scott, 2007). Cosmetics products, such as mascara, blush, foundation, and eye shadow, are quick to apply, impermanent, and may improve one's appearance in accordance with societal or personal beauty ideals, thus improving self-confidence (Miller \& Cox, 1982). Some women may also use cosmetics for hedonic enjoyment or aesthetic enhancement, not necessarily to bolster self-confidence. All of these motivations for use of cosmetics may result in expression of self-identity.

Numerous studies have been conducted on how women compare themselves to others and compare themselves to the ideal female American beauty. According to Lerner, Karabenick, and Stuart (1973), what a woman observes in the mirror is what she uses to measure her worth as a human being. Furthermore, some women can be their own worst critics as they look in the mirror; some women often tend to "over-think" their appearance and are often not accurate in assessments of their own appearances (Lerner et al., 1973). Previous research conducted on self-esteem has been related to how women feel about their size, shape, and body (Trampe, Stapel, \& Siero, 2007). Trampe et al. (2007) summarized across six studies and found that participants with body dissatisfaction were more affected by mass media images than women who were satisfied with their body image. Women who were unhappy with their body image were more prone to social comparison, affected by both attractive models and real women. However, only women who were dissatisfied with their bodies evaluated themselves negatively (Trampe et al., 2007). In general, self-esteem refers 
to how positively or negatively individuals feel about the subjective image of themselves that they have constructed (DeBord, 1997).

Not much research has been conducted on how cosmetics can improve a woman's self-esteem and self-confidence, and much of the research is over a decade old. For many women, wearing makeup can invoke one's self-image (LaBelle, 1988). Furthermore, according to Beausoleil (1992), many women report having different ways to apply their makeup depending on what they are expecting to do during a given day. Beausoleil also mentioned that women often partake in specific appearance practices to differentiate between natural looks and looks for special occasions and day and night looks.

Cosmetics serve as a strategy for getting acceptance from others and a symbol of the wearer's acceptance of society's aesthetic norms for women. Makeup styles at any point in history enhance women's features to look like the ideal beauty. Furthermore, Turner et al. (1997) found that media shapes, rather than reflects, societal perceptions of the female body, and that women's body image fulfillment is subjective, influenced by exposure to fashion magazines and other media.

Most models in U.S. magazines today are usually underweight, digitally airbrushed, and plied with a lot of makeup to look impeccably perfect, with only minor flaws remaining to make them look somewhat natural. Furthermore, models have a team of experts to make them look the way they do. Computer retouching has the capability to make models have higher cheek bones, fewer wrinkles, slimmer body parts, and many other enhancements (Media Awareness, n.d.). The image of what beauty is has been manipulated and deconstructed by the media, including magazines, and has many young adolescents suffering 
from insecurities and low self-esteem because they do not feel that they measure up to the impossible ideals presented in media ("Beauty Redefined," 2011).

The Barbie doll is an example of "a media product that creates a distorted body image in women" (MediaSmarts, n.d., para. 2). More than 1 billion Barbie dolls have been sold since her inception, and she has become "the face of the American dream," according to the Barbie historian Christopher Varaste ("Life in Plastic," 2005, p. 166). Barbie is known for her "perfect" looks, hair, and makeup. The doll is said to have the "Barbie effect" on younger adolescents, as their notions of what is attractive have been shaped by the doll. Barbie's body proportions and features are, nevertheless, not achievable by human women. By the early 1960s Barbie "opened new dreams for girls that were not accessible" ("Life in Plastic,” 2005, p. 169). Yet, this doll has impacted millions of young girls and played a huge role in their behavior at an early age. According to M. G. Lord, the writer of Barbie's biography, Barbie is “the most potent icon of the American's popular culture in the late $20^{\text {th }}$ century ("Life in Plastic," 2005, p. 166).

The beginning of a young tween or teen girl's first experimentation with applying cosmetics can be seen as a rite of passage as well as development toward a feminine identity (Cash, Rissi, \& Chapman, 1985). Indeed, it is during early menarche that the female adolescent becomes more concerned with her appearance (Kelson, Kearney-Cooke, \& Lansky, 1990). In American culture, young female adolescents tend to emulate beautiful women. Advertising tells us that makeup holds the promise to women of bringing out their inner beauty and transforming them to have higher self-esteem. 


\section{Issues of African American Women}

On any given day of watching television or looking through magazines, African American women face countless commercials of cosmetics advertisements from different companies promoting a new line of make-up, banishing-creams that reduce appearance of dark spots, anti-wrinkle creams that minimize the appearance of wrinkles, skin firming lotions, hair spray, hair dyes, hair relaxers, and many more beauty products directed towards women (Swain, 2012). In 2009, Essence magazine's Smart Beauty panel explored African American women's shopping experiences within the prestige beauty market (Smith, 2009). One study by the Smart Beauty panel found that African American women spent $\$ 7.5$ billion on beauty products each year, but when it comes to cosmetics, $80 \%$ more money was spent than women felt they should due to the fact that African American women often need to try out products first to find the right color, undertones, and pigments to match their skin color appropriately (Smith, 2009). The beauty products African American women looked for were brands they could trust featuring high quality ingredients and products that reflected their personality (Smith, 2009).

In addition, African American women were more likely to purchase products from aspirational labels such as Chanel and Versace, rather than purchase brands that were linked with celebrities (Smith, 2009). Make-up artist Sam Fine discussed issues African Americans face when looking for the right cosmetics products: "African American women are looking for affirmations of their own beauty through seeing spokespersons or models of color in ad campaigns for beauty products. One area that was void of faces of color were anti-aging products" (Smith, 2009, para. 6). Fine also noted that older African American women are 
"left out" by the beauty industry: "There's no face of aging in the African American community" (Smith, 2009, para 7).

An examination of African American women's use of style in general was found in a landmark study of adolescent girls by Parker et al.(1995). They found that African American girls' personal style involved making a statement and having a unique presence. Parker et al. indicated that African American girls involved in style, regardless of body type, frequently received positive compliments from African American boys, family members, and friends about "looking good" and "having a going on." This local and direct personal support may enhance feelings about appearance and self-esteem and encourage adolescent African American girls to experiment with apparel and cosmetics.

Extensive research has been done on how mainstream beauty standards have impact on White women (Swain, 2012). However, Duke (2002) conducted a study of Black and White girl's views of teen magazines. A total of 16 African American and 10 European American teen girls participated in interviews that traced their interpretations of the magazines. Duke (2002) found that the African American girls felt that mainstream teen magazines seemed to overlook their fundamentals concerns and interests and assumed that White dominance is normal and accepted throughout the mainstream media. The African American girls did not feel that the clothing, cosmetics, and grooming products advertised or discussed in the mainstream magazines fit their preferences or needs.

Parker et al. (1995) described that the ideal of beauty in mainstream U.S. society has been defined to a great extent as White, tall, thin, high cheek bones, and naturally pretty. The mainstream beauty ideal primarily fits White characteristics, which makes perceived beauty even more unachievable for Black women (“Beauty Redefined,' 2011). According to Swain 
(2012), while many European American women have fallen short of those standards of beauty, African American women are often "left out" from the ideal beauty standard. Hill (2002) found that African American men and African American women judged the attractiveness of women based on the lightness of their skin. Hill's study indicated that photographs of African American women with fair skin were rated the highest in attractiveness and those who were darker were given low ratings on attractiveness. However, these standards of beauty were more strongly held by the African American women more than by the men. Falconer and Neville (2000) surveyed African American women at a historically Black college and found that African American women who were content with their skin color had a more positive perception of their appearance than did African American women who are less content with their skin color.

Ironically, some women may feel offended by what Jones and Shorter-Gooden (2003) call the lily complex: "the belief that the only way to be beautiful is to look as close to "white" as possible" (p. 177). For example, Beyonce, Queen Latifah, and many more mainstream media representations of African American women have become overwhelmingly "whitewashed" - a transformation that results in lighter skin color, lighter makeup, straight long hair, and lighter eyes ("Beauty Redefined," 2011). Furthermore, when African American women are represented as a beauty icon in the media, most noticeably, they fit the White ideal, with lighter skin color and "ideal" White facial features as well as thinness ("Beauty Redefined,” 2011). Finding images of dark African American women has become impossible in the mainstream media ("Beauty Redefined," 2011; Swain, 2012). 


\section{Purpose}

This qualitative study was designed to make a contribution to filling the gap of knowledge regarding how cosmetics relate to African American women's attitudes toward the self and expression of self-identity. The purpose of this study was to explore African American women's attitudes toward cosmetics, how women use cosmetics, and how use of the products is related to women's self-confidence and perception of appearance. The population studied was young adult African American women who were residing in Pine Bluff, AR, or were undergraduate and graduate students who were enrolled during the 20122013 academic year at Iowa State University in Ames. All participants were African American women between the ages of 20 and 29.

The goal for this research was to explore African American women's experiences with the use of cosmetics, explicitly looking at the use of cosmetics products in relation to African American women's attitudes, self-confidence, and self-identity. Not much research has been conducted on the role cosmetics play in African American women's lives or how cosmetics make them feel about the self. It is important to understand this underserved market as well as to expand understanding of ethnic minority consumers in U.S. society.

The study is an effort to explore African American women's concerns and beliefs about the use of cosmetics. The inspiration to explore this topic on cosmetics came about as a result of the researcher's own experience as an African American woman who wears cosmetics and understands how cosmetics play a role in her own attitude, self-confidence, and self-identity while using cosmetics products. 


\section{CHAPTER 2. LITERATURE REVIEW}

This review, which presents the background for an investigation of African American women's use of and attitudes toward cosmetics, has been divided into five sections. The first section briefly explores the historical precedents underlying the use of cosmetics in ancient periods. The second section examines the issue of how media affect women's perception of beauty and women's self-image and self-esteem. The third section provides a discussion of how women use cosmetics to meet the standards of others and how this may relate to their self-esteem and self-concept. The fourth section focuses on how physically attractive women tend to be perceived as more successful in the working environment. The fifth section examines the use of cosmetic surgery. Following the literature review is a discussion of theories providing a beginning theoretical basis for the inductive study.

\section{History of Cosmetics}

Draelos (2001) noted that "the history of cosmetics is an important part of how color is used to adorn the body in modern society" (p. 175). Draelos continued:

The use of eyelid cosmetics was recorded as early as 4000 BC. Green powder made from malachite was heavily applied to both the upper and lower eyelids, accompanied by dark kohl eyeliner paste composed of powdered antimony, burnt almonds, black copper oxide, and brown clay ocher. (p. 175)

Draelos also noted that the cosmetic pastes were put in a pot and mixed with saliva.

In Japan, lipstick was made of crushed petals of safflower which was used to paint the eyebrows and edges of women's eyes and lips (Chaudhri \& Jain, 2009). Also, rice powder was used for coloring of the face and back. In the traditional culture of Japan, women having whitened skin was common. 
In the ancient Egyptian period, cosmetics such as face paints, oils, solids, and fats (ointments) all were considered as cosmetics for the skin (Lucas, 1930). The ancient Egyptians took great pride in their appearance and in cleanliness (Chaudhri \& Jain, 2009).

Throughout past centuries, cosmetics were applied as part of a variety of ceremonies and rituals. For instance, during the Middle Ages in Europe, economic status determined how much time a person had to spend outdoors. People in the lower classes had to work outdoors, whereas those in the upper classes had more leisure time and stayed indoors more, which kept their skin pale and unexposed to the sun (Chaudhri \& Jain, 2009). Thus, European American men and women used white powder on their body to appear more aristocratic (Chaudhri \& Jain, 2009).

According to Wells and Lubowe (1964), the first true facial foundation was developed in 1936 by Max Factor as a cake makeup that was widely used by women. This product added facial color as well as a velvety look. Since that time, vast arrays of cosmetics lines have been expanded tremendously. According to Draelos (2001), facial foundation is a popular facial cosmetic with the greatest impact on the health of the skin (p. 176).

\section{African American Cosmetics}

During the Jim Crow era, some African American female entrepreneurs were successful, despite racial segregation and economic discrimination (Willett, 2010). Around the beginning of the 20th century, the beauty pioneers Annie Turnbo and Madam C. J. Walker paved the way for companies like Avon and Mary Kay cosmetics (Willet, 2010). Annie Turnbo and Madam C. J. Walker created hair supplies and creams so that African American women too can have supplies to make their hair and skin beautiful. These women developed a hair product used to straighten African American hair without damaging the 
hair. Annie Turnbo then created her own hair line of beauty products for African American women (Willet, 2010). However, as a Black woman, Turnbo was denied access to regular distribution channels. Turnbo and her assistants decided to sell her products door to door (Lee, 2012) to introduce consumers to her products For effective promotion, advertisements were displayed in African America newspapers, and agents were hired and trained to serve as local sales associates (Willet, 2010). During this period, Turnbo hair products sales grew successfully and expanded nationally (Willet, 2010). The Black-owned company did not include many cosmetics products but was able to successfully market face powder in darker shades

Madam C. J. Walker created many beauty and hair care products for African American women. Walker developed her own scalp conditioner and healing treatment formula called "Madam Walker's Wonderful Hair Grower” for African American women who were suffering from hair loss. Moreover, with the advertising knowledge of her husband Charles Joseph Walker, she was able to market her products through her homebased business. Walker traveled throughout the South and Southeast demonstrating to African American women door-to-door (Willet, 2010).

In the 1920s Walker offered face powder and skin care products to drugstores for sale to African American women. During that time controversy was stimulated because many companies decided to sell skin bleachers to consumers to have lighter skin tones. Walker declined to market any skin bleaching products within her company. However, skin bleaching products became popular after her death in the 1930s (Willet, 2010).

By the early $20^{\text {th }}$ century many Black-owned companies manufactured skin-bleaching creams, but hardly any advertised them. However, according to Willet (2010), White-owned 
manufacturing companies did display crude images of such products such as women's faces split in half, one side black and one side white. Nevertheless, during the 1920s and 1930s more sophisticated African American beauty industry advertisements were evident in chain stores, improving perceptions of race and promoting positive self-images to encourage increased social mobility (Lee, 2012; Willet, 2010). Commercial hair and cosmetics products became more common in women's lives. These sophisticated advertisements connected beauty products to female popularity, glamour, and romantic status (Willet, 2010). Throughout this process, the African American beauty industry continued to grow successfully and expand product lines (Willet, 2010).

\section{Brand Loyalty and African Americans}

NewMediaMetrics, a strategic marketing company, measured Emotional Attachment $^{\mathrm{TM}}$ to brands and media and found that African Americans were significantly attached to brands they used more than were European Americans. Both African Americans and European Americans between ages 18 and 54 were surveyed on 350 brands, and $73 \%$ of the brands studied showed higher attachment among African Americans consumers than among European Americans (Sampey, 2012). In a recent study, NewMediaMetrics found that African Americans are among the most brand-loyal consumers in the nation compared to European American consumers.

African American consumers, in comparison to European American consumers, were found to be significantly more attached to brands and services such as: Lexus, General Motors, Slim Fast, UPS, Tide, Jell-O, Doritos, Dawn, Oreos, Betty Crocker, Walmart, the Gap, Lowe's, Levi's, Macy's and many other brands and services (Sampey, 2012). Cofounder of NewMediaMetrics Gary Reisman stated: "Clearly, the African-American 
consumer is more passionate about brands than the Caucasian consumer," and "We also see stronger attachment to media properties, so if marketers cross reference the brand data to the media data, they'll make more effective use of their media spending in reaching both consumer segments" (Sampey, 2012, para, 6). The NewMediaMetrics study showed that for media African American adult consumers were more attached to 60 broadcast and cable networks (24\%) compared to European American adult consumers, whose average attachment levels were 17\%. Moreover, African Americans were more attached to websites and digital properties at $18 \%$ attachment level compared to $13 \%$ for European Americans (Sampey, 2012).

NewMediaMetrics co-founder Denise Larson also indicated, "Perhaps the overall passion that African-Americans have for brands will be a 'wake up call' for marketers to strategically think of their brands from the perspective of consumer diversity, especially when it comes to budget and spending priorities" (Sampey, 2012, para 8). The money that African Americans spend on goods and services is vital to mainstream marketing of products. Focus on diverse consumers provides a better way to enhance understanding of African American and other ethnic groups' purchasing power.

Wakefield and Inman (2003) proposed that consumers are usually less price sensitive when purchasing products and services that have hedonic value rather than only practical value. The hedonic products purchased are consumed, in part, for fun and pleasure, so saving may not be the strongest concern for consumers when deciding to buy something for hedonic reasons (Dhar \&Wertenbroch, 2000; Khan, Dhar, \& Wertenbroch, 2004). Further research of African American consumers and their spending on hedonic products like cosmetics is definitely needed. 


\section{Media and Ideal Beauty Socialization}

In America, women continuously look for ways to change their appearance to fit the American ideal of beauty, images of which — including clear skin, flushed cheeks, blue eyes and pouty red lips — saturate media advertisements (Poran, 2002). Idealized images

portrayed in media are different from the way women view themselves and other real women.

Beauty pageants are an example of the media using cultural ideals to socialize young women by showing them limited types of feminine beauty schemas presented as ideal beauty (Lynch, 2007). In beauty pageants, young women are made to appear alluring with makeup, high heels, long flowing hair, and bathing suits as they walk around the stage to be judged by others (Freedman, 1986). Beauty pageants have been a part of American culture for many decades. The Miss America Pageant started in 1921 as a "bathing beauty" contest (Copeland, Grodnitzky, \& Cowen, 2002). Beauty pageant contestants are considered to be like Barbie dolls, with perfect proportions and flawless makeup.

Indeed, the media increasingly manipulates the ideals for women's appearance (Lynch, 2007). When women compare themselves with idealized media images, it can have a positive or negative effect on women's perception of their own female beauty (Jones \& Buckingham, 2005; Monro \& Huon, 2005; Pompper \& Koeing, 2004). The media can a have a positive effect in how some women perceive their own identity. For example, a woman who feels she is in control of herself and who is proud of her own body image and appearance may feel that the media exemplifies those feelings within her ("Body Image," 2012). In research studies, African American women have been found to be comfortable with their own body types and self-images (Martin \& Baugh, 2011). However, there are 
conflicting results. Since slavery, the African American community has been judged as not meeting physical appearance norms in the United States. This has created a dynamic where some African American women become dissatisfied with their physical appearance and choose to alter that appearance to reach what is considered society's view of beauty (Martin \& Baugh, 2011). For instance, Poran (2006) provided direct evidence of how African American women have been negatively influenced by the mainstream media's standards of beauty. Some of these examples include pressuring African American women to become thinner, to fit the preferences imbedded in European American men's standards for women's attractiveness, and creating dissension among communities of African American women about what is appropriate and attractive. Because the mainstream media has promoted one standard of beauty, Poran (2006) suggested that African American women are not completely protected by the "Black Culture" from negative body images. While some research has found more positive body satisfaction among African American girls and women in comparison to European American girls and women (e.g., Parker et al., 1995), the reasons for satisfaction and extent that it shapes appearance concerns and behaviors are not well understood.

\section{Cosmetics and Self-Esteem}

The existing literature considers cosmetics usage from varied angles. Robertson, Fieldman, and Hussey (2008) looked at how women's personality traits predicted their use of cosmetics. The aim of the study was to understand the psychological motivations of why women used cosmetics. Robertson et al. (2008) found that the use of cosmetics was positively associated with traits such as self-perception, self-awareness, conformity, and introversion and negatively associated with self-confidence, self-esteem, physical 
attractiveness, and emotional stability. Furthermore, Robertson et al. (2008) suggested that some traits make women more aware of an interest in their physical appearance which results in the desire to manipulate appearance according to an image that is ideal and more conforming to social preferences and expectations.

Cosmetics companies produce products to help consumers produce the ideal face. Many women use makeup to meet societal standards and to gain attention from the opposite sex but also to receive compliments from other women (Kelson et al., 1990; Scott, 2007). Cosmetics offer the promise of change toward the ideal image (Bloch \& Richins, 1992). Scott (2007) stated that "cosmetics are a quick means of improvement versus more longterm, laborious work such as diet and exercise" (p. 3). For example, an online study reported a survey of 1,292 women in which $44 \%$ of women were dependent on cosmetics for selfesteem (Renfrew Center Foundation for Eating Disorders, 2012). Most of the women had negative feelings when they were not wearing makeup, which made them feel unattractive (Renfrew, 2012). The study was conducted on behalf of the Renfrew Center Foundation (a nonprofit organization) to show that increasing dependency on cosmetics products is boosting self-esteem and attractiveness

In the study women were asked what their reasons were for wearing makeup. Among respondents, $16 \%$ of women felt unattractive when not wearing cosmetics, $14 \%$ felt selfconscious without makeup,14\% felt naked without makeup, and 3\% of women felt more attractive without makeup. Moreover, $27 \%$ of the women reported wearing makeup since they were 13 years old (Renfrew, 2012), the age at which young adolescents tend to start maturing physically and become more aware of their appearance. This data indicated that the vast majority of women feel that wearing makeup enhances their appearance and that it is 
normal and accepted in society to change one's self. However, Adrienne Ressler, the Renfrew Center's national training director and body image expert, stated that "there is concern, however, when makeup no longer becomes a tool for enhancement but, rather a security blanket, which conceals negative feelings about one's self, self-image and selfesteem” (Renfrew, 2012, para. 3).

\section{Cosmetics and Success}

Many women feel that physical attractiveness and beauty are important and that attractive women have more opportunities to succeed in their professional and social endeavors if they are attractive (Etcoff, Orbach, Scott, \& D’Agostino, 2004). In addition, individuals who appear more physically attractive often gain higher status and social rank due to the stereotype that what is beautiful is good and, subsequently, what is not beautiful is bad or not so good (Dion, Berscheid, \& Walster, 1972). Due to these widely held assumptions, most people believe that putting one's best face forward will help one succeed in life. Cosmetics help in shaping an appearance that fits attractiveness norms, so they are enlisted to literally put the best face forward.

In a recent study, described in an article by Catherine Saint Louis (2011) in the New York Times, women wear makeup to increase other people's perceptions of their likeability, competence, and trustworthiness (para. 1). That study, designed and conducted by researchers from Boston University and the Dana-Farber Cancer Institute, used photographs of 25 women between 20 and 50 years of age from different ethnic backgrounds (European American, African American, and Hispanic), each of whom were photographed barefaced and also with varying amounts of makeup applied (Saint Louis, 2011, para. 4). Both the 149 adults who looked at the photos for 250 milliseconds and the 119 different adults who looked 
at the photos for a longer period of time judged the women wearing makeup as more competent than bare-faced women (Saint Louis, 2011, para. 5).

Furthermore, Nancy Etcoff, assistant professor of psychology at Harvard University, stated that "there is evidence that women feel more confident when wearing makeup, a kind of placebo effect" (Saint Louis, 2011, para. 2). Women wear makeup to feel more appealing and boost their self-esteem, which may help in their confidence and, hence, performance when applying for jobs and on the job. Indeed, research has shown that external appearance and frequent cosmetics use affect professional success positively (Hamermesh \& Biddle, 1994; Marlowe, Schneider, \& Nelson, 1996), indicating that there is some role of beauty in the labor market. Furthermore, (Hamermesh \& Biddle, 1994) found that people with belowaverage salaries tended to be less attractive and had lower salaries than did average-looking workers; workers with higher salaries tended to be more attractive-looking individuals. The labor market tends to place more attractive people into better paying occupations in which their looks may add to their productivity (p. 1192).

Ligget (2012) looked at how the recent economic recession influenced college-aged women, who were found to purchase more cosmetics to attract a mate, presumably to bolster their chances for economic support in the future. Other literature has shown that women who were waitresses and wore cosmetics received better tips than did waitresses who did not wear cosmetics (Gueguen \& Jacob, 2010). Altogether, these studies show that cosmetics use by women enhance the perception of physical attractiveness and positive traits, perhaps leading to gains in self-esteem and confidence which enhance work and economic success. 


\section{Cosmetic Surgery and Non-surgical Cosmetic Technologies}

Over the past decade, an increasing number of cosmetic surgeries have been performed in the United States. According to the American Society for Aesthetic Plastic Surgery (ASAPS) nearly 8.4 million cosmetic procedures were performed in 2011, and a great percentage involved surgery on the face (ASAPS, 2012).

A group of researchers from Turkey conducted a study recently to understand what factors motivated women to change their facial appearance. The results showed that young adult women in their 20s were concerned with the nose and skin, women in their 30 s and 40s were concerned with their skin and the area around their eyes, and women in their 50s were most concerned with the area around their eyes and their jaw line (Sezgin, Findikcioglu, Kaya, Sibar, \& Yavuzer, 2012).

Moreover, the researchers wanted to understand why women desired to alter their facial features and what led women to seek so-called perfection. They found that women were not pleased with what they saw in the mirror. According to Sezgin et al. (2012), when a woman looks in the mirror, she focuses mainly on the parts her face she desires to change. The 200 women participating in the study, who were patients consulting at a cosmetics surgery outpatient clinic, were asked:

which part of their face they concentrated on when they look in the mirror, which part of the face they noticed on other women, and what concerns them most about their own face, and any worries to change any of their facial features. (Sezgin et al., 2012) Although cosmetic surgery is considered to be very important to some women, a number of women are satisfied with their appearance. However, women who have a deep desire to have 
cosmetic surgery passionately hope to change their physical appearance because they are unhappy with their facial features (Sezgin et al., 2012).

Tyner (2008) stated that non-surgical enhancement technologies, which are undergoing a huge increase in use, are designed to increase and improve one's appearance. Non-surgical cosmetic technologies include treatments such as Botox, skin peels, wrinkle fillers, and body wraps. These technologies may continue to be used by a growing number of consumers, in addition to regular over-the-counter cosmetics, as a part of the arsenal of products and procedures to modify the face to fit societal ideals. Cosmetic products, however, are more temporary and readily removable adjustments to the face.

\section{Potential Theoretical Foundations}

\section{Black Feminism}

Hill-Collins (1990) defined Black feminism through four major themes, all generated from Black women's perspectives. First, Black women can empower themselves by selfdefinitions and self-valuations which allow Black women to confront and dispel negative images of Black women and replace the images with positive identities. Second, the overarching societal structure of domination within gender, race, and class are challenged by Black women. Third, intellectual thought and political activism are intertwined in Black feminism. Finally, Black women are aware of their distinct cultural heritage that gave them skills and energy to resist discrimination.

Feminism evolved through three major waves of social change (Krolokke \& Sorensen, 2006). The first wave, emerging in the late $19^{\text {th }}$ to early $20^{\text {th }}$ century, concentrated on equality and freedom for women in the liberal rights movement. The second wave, in the 1960s and 1970s, linked to the modern civil rights movement (Taylor, 1998). By the mid- 
1990s, the third wave of feminism “embraces ambiguity, diversity and multiplicity in transversal theory and politics" (Krolokke \& Sorensen, 2006, p. 2). During slavery up through the mid-1800s, African American female slaves were made to assimilate to the American culture of that time; slaves were stripped of their cultural identity, religions, their past life, and clothing (Sanders, 2011) and devalued because of their non-White features and White-imposed status as barely human. However, by the end of the $20^{\text {th }}$ century, African American women have come to assimilate within the American mainstream standard of beauty, which has broadened slowly to incorporate more diversity beyond White majority narrower constructions of beauty.

\section{Social Comparison Theory}

Researchers have used a variety of theoretical paradigms for studying the process of how women view themselves and how their self-esteem is related to personal comparisons to other women. Festinger's (1954) social comparison theory is the most commonly used comparison theory (Botta, 2000; Irving, 1990).

An important component of self-concept is how one compares the self to other individuals (Kaiser, 1997). Festinger (1954) noted that people typically evaluate themselves by comparing themselves with others who are somewhat more attractive or to others who are less attractive than the self. The speculation is that higher-valued individuals are typically those with whom one chooses to become familiar and who generally have more effect on one's self-esteem as an outcome of social comparison processes (Bunnk \& Mussweiler, 2001). Social comparison can take place among people who are not involved in a certain group together or have no interaction with one another; for example, individuals may compare the self to a valued celebrity or fashion models. 
The main research in social comparison theory has focused on two main types of social comparison: downward social comparison and upward social comparison. In downward social comparison people view others as less attractive or worse off than themselves to fortify the sense of self as better or valuable. In contrast, some women engage in upward comparison to feel better about themselves. Upward comparison allows some women to aspire to ideals presented by more attractive individuals; the upward comparing women in some cases feel better about the self when inspired by the ideal. More common, however, is that many women have great dissatisfaction with their own personal appearance after upward comparison, which can lead to feeling substandard and needing to repair their imperfections. On average, women tend to make upward comparisons, which provide the opportunity for them to become displeased with their body and experience shame, dissatisfaction, weight anxiety, negative moods, and low self-esteem (Fredrickson \& Roberts, 1997; Tiggemann \& McGill, 2004).

Willis (1981) suggested that downward comparison occurs within "situations in which frustration or misfortune has occurred that is difficult to remedy through instrumental action" (p. 245). In essence, an individual's self,can be enhanced by comparing the self to others who are worse off. However, Willis (1981) also proposed that downward comparison can threaten individuals causing them to look for downward comparison in others. For instance, some women may feel threatened when another women has on makeup and looks more attractive; the threatened woman may then look for flaws in the attractive woman to make herself feel better about her outward appearance.

Social comparison theory is a useful framework for studying cosmetic use and provides a framework for understanding varied pathways of psychological functioning 
(Bunnk \& Mussweiler, 2001). The importance of attractiveness to women increases their concern about their own appearance, which adds to the chances that they will compare themselves to others. Comparisons to others may provide information about trends and trigger motivation to use cosmetics. In Western culture not only do individuals desire to evaluate their abilities, but they also feel pressured to improve, which compels individuals to make efforts to become better in comparison to others (Wood, 1989). One way to improve after upward comparisons on the part of women who feel unattractive is to buy and apply more cosmetics.

\section{Symbolic Self-Completion Theory}

Symbolic self-completion theory explains how individuals define themselves.

Wicklund and Gollwitzer (1982) argued that many individuals attempt to label themselves to clarify their identity. A key component to the theory of symbolic self-completion is that an individual who is incomplete in an area of self-definition must be active in pursuing selfdefinition in order for self-symbolizing to occur (Wicklund \& Gollwitzer, 1982; Gollwitzer, Wicklund, \& Hilton, 1982). An individual may use props such as clothing or cosmetics to foster a sense of self-completion (Wicklund \& Gollwitzer, 1982). Wicklund and Gollwitzer also noted that individuals who feel less complete are likely to feel insecure in roles or statuses to which they are committed. For example, individuals who feel valued by other people are likely to have higher status. Individuals who are ridiculed by others are not as likely to have higher status. When symbols of a person's identity are recognized, the identity of that person is validated; the person will feel complete when his or her identity is affirmed (Wicklund \& Gollwitzer, 1982). 


\section{Looking Glass Self, Self-Concept, and Identity}

According to Mead (1934), the looking glass self is a process through which a person sees him or herself through others' perceptions. Individuals learn who they are by the way others react to them (Mead, 1934). Gregory Stone (1965) noted that appearance and dress shows others who we are and reveals our identity. Stone also proposed that our appearance tells our past, future, and present time which lets others anticipate what is about to occur in our everyday lives (Charon, 1985). For example, some women may wear cosmetics when they are going out at night with friends or just for special occasions. The use of cosmetics applied to the face can anticipate the actions of an event a woman may be about to attend.

Charon (1985) proposed that advertisements define the situation for some consumers, sending out messages that indicate "you need this product," or "this product is better than others." However, interpersonal influences may also define the situation, of one's self and for others, overriding media persuasions. Cosmetics advertisements can be considered as an example of how the media attempt to define the situation for women, emphasizing that a certain cosmetics product will make her skin flawless or make her eyes pop with a certain color of eye shadow. Interacting with significant others about advertisements can define what cosmetics product a woman may purchase. Goffman (1959) pointed out that individuals try to impress others by presenting a part themselves that they choose to display which will influence people's definition about themselves. Some women may wear cosmetics to impress others and display that she cares about her appearance. In essence, cosmetics help a woman present an idealized version of the self (Goffman, 1959).

Schmitt and Allik (2005) defined self-esteem as a person's overall belief in worthiness of the self. Judgments' relating to self-worth are the evaluation component of 
self-concept. Some researchers assume that when a person has high self-esteem, the selfconcept is likely to be positive (Pajares \& Schunk, 2001). Rosenberg and Pearlin (1978) proposed that someone with positive self-esteem sees the self in a positive sense and sees the self as a nice person. Indeed, self-concept theorists (Tesser \& Campbell, 1984) noted that an individual will do everything to avoid forming negative self-conceptions. Wearing make-up to receive positive reviews makes a woman feel attractive and valued and may help to enhance her self-esteem.

Gottfredson (1985) recognized that self-concept includes important components such as identities and self-esteem. Identity is an important concept in this study. Social identity theory focuses on how a person's social identity is defined within a group (Tajfel \& Tuner, 1979). Groups that a person is involved in give the person a sense of social identity through belonging. Guy and Banim (2000) linked identity to women's involvement with clothing that they wear to enhance their self-presentation in everyday life. Guy and Banim (2000) found that women use their clothing to articulate their identity and self-image. The women explained how their clothing enhanced and projected a positive image of themselves, expressed how some clothing was unflattering to their bodies, or accidentally caused negative self-presentation to others.

Some women may apply cosmetics to project confidence with their own skin, enhance their facial features or make a good impression on others. Moreover, some women may be afraid to identity with cosmetics due to the fact they do not know how to apply cosmetics correctly, which could lead to them receiving negative comments regarding their makeup. Fear of mistakes in putting a face together could lead some women to do personal research about cosmetic application. 


\section{Self-Objectification}

Fredrickson and Roberts (1997) proposed objectification theory as a framework for understanding the psychological effects of being a woman in Western society. On a regular basis women are faced with objectifying images and messages within the media (Wolf, 1991), thereby encouraging women to objectify the self. Self-objectification arises when a person or society emphasizes focus on physical appearance, beliefs about importance of appearance, and internalization of appearance ideals (Lee \& Johnson, 2009). Objectification theory foretells that an observer's perspective on one's body (self-objectification) leads to negative body image and mental health outcomes (Fredrickson \& Roberts, 1997). Selfobjectification has been established in various studies and is predominantly powerful among women in the United States. Using cosmetics to improve appearance may be a consequence of objectifying the self.

Women in Western societies are socialized to adapt to taking an outsider's or other's view of the self as a physical object (Lee \& Johnson, 2009). For example, when a woman is being evaluated according to her physical characteristics, the woman tends to adopt an observer's view of the self in order to influence and anticipate others' perceptions about herself. The visual inspection and experience of self-objectification can differ between individuals and within certain situations (Lee \& Johnson, 2009). However, there is much social encouragement for women to maximize physical attractiveness and present an idealized version of the physical self to fulfill her female role (cf., Goffman, 1959). Cosmetics can be used to help construct an idealized female presentation of self. 


\section{Issues of Power}

Weitz (2001) described "power" as having the ability to control or influence others while trying to reach desired goals. Foucault (1979) saw women as having "docile bodies" or bodies that are subject to power struggles. Foucault (1979) theorized that power in social relationships makes bodies submissive to discipline and weak to resistance to discipline. Weitz, on the other hand, saw that taking charge of the body through grooming practices could impart some power to a woman over social relationships.

Weitz (2001) explored how some women used their hair to gain power in both their personal and professional lives. For instance, for one of the African American women Weitz interviewed power was bittersweet; she transformed herself into a conventionally attractive person changing her hair and appearance to attract more friends and the opposite sex. Although, the woman revealed that she did not like the process of transforming into the conventionally attractive person, she felt like she was transforming into a different, more acceptable person. Power gained this way has less effect of resistance, according to Weitz (2001). When African American women change their outward appearance and behavior, they may tend to adopt an identity to satisfy Black or White men rather than to satisfy themselves (Jones \& Shorter- Gooden, 2004, p. 7). Weitz (2001) found that something as simple as women cutting their hair can provide awareness of how women navigate within social structure and cultural expectations. African American women "shift to accommodate differences in class, as well as gender and ethnicity" (Jones \& Shorten-Gooden, 2004, p. 7). Weitz (2001) focused on resistance and accommodation seeking power through hair and mainstream attractiveness. 
Scott (1990) and Stombler and Padavic (1997) measured resistance in different ways. Scott (1990) looked at "actions that reject," and Stombler and Padavic (1997) suggested “relying on actors' assessments of their intent" (cited in Weitz, 2001, pp. 669-670).

However, Weitz (2001) argued that women's accommodation and resistance to standards can be found in women's self-presentation with different styles of hair. It is possible that women may take control to both accommodate and resist social forces by applying cosmetics The power implications of resistance and accommodation are complex and multifaceted.

\section{Research Questions}

The following research questions guided the study:

1. What influences women to buy cosmetics? What types of cosmetics do African American women purchase?

2. What are patterns of use of cosmetics? Do African American women wear them for some situations only? Do African American women use makeup differently depending on the social situation in which they expect to participate?

3. How does wearing and not wearing cosmetics relate to African American women's self-identity? Do they compare themselves to others, and if so, do they report upward or downward comparisons?

4. Do African American women feel they receive varied responses from others when wearing cosmetics?

5. Do themes about use of cosmetics for self-completion arise, and if so, for what types of social roles? 
6. Do issues related to minority ethnicity arise in relation to availability of appropriate cosmetics on the market? Are there power issues inherent in African American women's involvement with and access to cosmetics?

This qualitative study sought to make a contribution to filling a gap in the literature by exploring what can be learned from African American women, in their own words, about their use of cosmetics products. Almost no attention has been given to ethnic minority groups and their use of cosmetics in defining and expressing the self. 


\section{CHAPTER 3. METHODS}

In-depth, face-to-face interviews were conducted to gain insight into African American women's usage of and attitudes toward cosmetic products and the relationship of cosmetics use to self-identity. In conducting semi structured interviews, the "goal is to explore more openly and to allow interviewees to express their opinions and ideas in their own words" (Esterberg, 2002, p. 87). A series of questions guided the interview. The researcher made sure each participant had the opportunity to tell her own story.

\section{Participants}

\section{Sample}

To participate in this study, a woman had to be between 20 and 29 years of age and agree to meet with the interviewer for a face-to-face interview. The purpose of the nine-year age range was to capture the opinions of young adult women in a variety of roles and lifestyles.

This study employed a sample of 18 individuals. Minority women's networks and snowball sampling was used to recruit participants. "In snowball sampling, a key informant, usually initial participants and/or known acquaintances of the researcher, referred the researcher to other potential participants such as friends, acquaintances, or others they feel may be appropriate for the study" (Tyner, 2008, p. 30). The use of the snowball strategy allows participants to gain an initial level of trust with the researcher who knows members of the participant's community (Esterberg, 2002).

The participants recruited were African American women who were residents of Pine Bluff, Arkansas, and African American women living in Ames, Iowa, and attending Iowa State University (ISU). Interviewing took place over the course of the 2012-13 academic 
school year. Recruitment was done by a form of snowball sampling and with the help of the ISU Minority Students Office to advertise the study to African American students (Appendix A). An African American professional network for Southeast Arkansas was utilized to solicit participants from the southeastern part of Arkansas (Appendix A). Although, the researcher used snowball sampling to a limited extent, many of the participants were invited to participate in the study via the two widely broadcast (but membership only) networks.

When friends, acquaintances, and colleagues helped recruit key informants who were appropriate for the study, they were asked to inform the participants that the researcher would follow up with a phone call to set up a time and place for the interview.

\section{Data Collection}

The researcher met with the respondents to the ads and snowball sampling for a faceto-face interview that was scheduled for about an hour. The participants had the opportunity to select the place and time so that the interview would be comfortable and convenient. The interviews took place, for example, in a private meeting room, a home, or a quiet area in a building on campus where the participant could speak openly.

At the start of the interview, the researcher summarized the purpose and procedures of the study. The participants then read and signed the informed consent document (Appendix B) and completed a brief questionnaire about demographic characteristics (Appendix C).

The interviews included two types of questions: semi structured and open-ended questions (see Appendix D). Ad hoc probing for depth of responses was conducted. The interviews were audio recorded with permission from the participants. Participants also were informed that they could skip questions or refuse to participate at any time and that not 
participating would not result in any penalty or loss of benefits. The individuals were informed that there were no right or wrong answers and that they should answer each question honestly. Details of the study were submitted to the ISU Institutional Review

Board, which determined that the study was exempt from human subjects protections regulations (Appendix E).

\section{Compensation}

Participants were compensated for participating in this study with a \$5 Target gift card to thank them for taking the time to participate in the interview. No other compensation was offered.

\section{Confidentiality}

The data collected from the participants were kept confidential. All identifying information of the participants were omitted from the study materials. The signed informed consent forms were kept separate from the data, and codes linking to consent forms were not placed on the questionnaires or transcripts. The researcher kept transcripts and audio recordings in a locked file for security. Transcribing was done in a private room or with earphones so that voices of the participants on the tapes could not be heard by others. The researcher also informed participants that, should they leave the study at any time, the transcripts and recording would be destroyed immediately. All audio recordings were destroyed within six months of data collection. Data collected from the study, such as quotes, were reported in ways that would not disclose the respondent. Pseudonyms were used in any reporting of quotes. 


\section{Data Analysis}

Data analysis involved reading through at least 25 percent of the interview transcripts for concepts, developing key themes from coding by identifying location of themes in the data, and drawing connections between the discrete pieces of data (Strauss \& Corbin, 1990). The inductive analyses proceeded by drawing insights for each research question. Comparisons and contrasts were made across participants.

Several measures were taken to increase trustworthiness and dependability when collecting the data and during analysis process (Tyner, 2008). First, during the coding process I met with my major professor to discuss the coding guide. Second, after interviews were conducted I listened to the recordings. Third, I had a second coder check my work and I hired a transcriber for my recordings.

During the axial coding processes, the researcher searched the data for (a) relations among themes and (b) patterns among those relations (Strauss \& Corbin, 1990). The researcher looked at the type of contexts in which various themes or meanings were found. Finally, the researcher used a selective coding process to synthesize and refine meanings and relationships found within the data (Strauss \& Corbin, 1998). To this end, the researcher coding guide was developed using the observations made at previous stages in the analysis process, linking them back to the literature and the data set, and finally, developing themes linked to the data in the context of the literature and theoretical frameworks.

Many measures were taken to increase trustworthiness and dependability of the data collection and analysis processes. First, the coding guide was checked many times by the major professor to ensure accuracy and significance of each theme and category. In addition, coding of data was also checked for trustworthiness by a fellow graduate student, well 
experienced in qualitative methods. The auditing or coding check was conducted on $25 \%$ of the data already coded by the primary researcher. Next, an interrater reliability was calculated by subtracting total disagreements from total agreements and dividing that number by total number of coding decisions (Lombard, Snyder-Duch, \& Campanella-Bracken, 2002). The intercoder reliability for $25 \%$ of the entire data set was $97 \%$. All disagreements in coding were negotiated between the primary researcher and coding auditor. The negotiations resulted in adjustments in coding of the remaining unaudited data.

Finally, theories were enlisted when they provided understanding of the data. An inductive use of theories was undertaken, in that some theories not yet discussed in the literature review may have applicability and previously discussed framework theories might not fit the data well. Patterns in responses and themes in the data may have emerged that reflect theoretical explanation not previously planned by the researcher. The researcher used multiple theories to help explain and understand the participants' experience using cosmetics, allowing for "triangulation" of theoretical understanding (Denzin \& Lincoln, 1998).

\section{Researcher Background}

The training and background of the researcher may have impact on questions asked and interpretation of data. To minimize bias, the researcher examined her background to understand the perspectives she brings to the research.

She was inspired to explore this topic on African American women and cosmetics because of her own experiences as an African American woman. She had often heard women talk about cosmetics and express how they had trouble finding the right foundation to match their skin complexions. She was born and raised in a southern city in Arkansas and was attending school in Iowa, so had experience living in both locations studied. Living in 
Iowa, she was faced with many barriers on finding cosmetics that worked for her skin complexion. Exploring this topic with other African American women from Arkansas and Iowa helped her understand that cosmetics to African American women are essential and highly enjoyed even if one did not wear the cosmetics on an everyday basis.

When this researcher first went shopping in Iowa, she noticed that the cosmetics products offered in the stores had lighter shades of foundations. She was disappointed that the cosmetics products for African American women who had darker skin were limited. She remembered asking herself, "Do other African American women feel left out?"; "What type of cosmetics do other African American women use?"; and "Where can I find and purchase cosmetics that will work with my skin tone?"

However, she eventually started to order cosmetics online and whenever she went home over break, she purchased cosmetics while she was home. She became extremely pleased that she could actually select a foundation that would blend perfectly with her skin and would not have to worry about using cosmetics that made her skin look dull. Experiences such as these influenced her to explore whether other African American women from her home town and in Iowa had similar encounters. 


\section{CHAPTER 4. RESULTS AND DISCUSSION}

This chapter presents the findings and some discussion of the findings, organized around the major themes identified from participants' responses to the qualitative questions. The chapter begins with a description of the participants who participated in the study, followed by an in-depth discussion and analysis of major themes that emerged from the qualitative analysis. The major findings acquired from the data related to: (a) memory, (b) shopping experiences, (c) self-enhancement, (d) brand preference, and (e) media sources. Each of these topics are interconnected but will be discussed separately to gain an understanding of the participants' views of the use of cosmetics in relation to their selfesteem and self-identity.

\section{Overview of Participants}

Participants in the study included 18 African American women between the ages 20 and 29 years. Eleven of the participants resided in Pine Bluff, Arkansas (see Figure 1), and seven, who were undergraduate or graduate students at a university located in Iowa, currently were living in Iowa but originally came from other cities around the country (Pine Bluff, AR; Atlanta, GA; Chicago, IL; White Plains, NY; Orlando, FL; Washington, DC; see Figure 2). Each participant had some college education: Thirteen participants were undergraduate students, two were Masters students, and three were doctoral students (see Figure 3). Out of the 18 women interviewed, three were working professionals in the workforce. All the participants identified themselves as single or never married. 


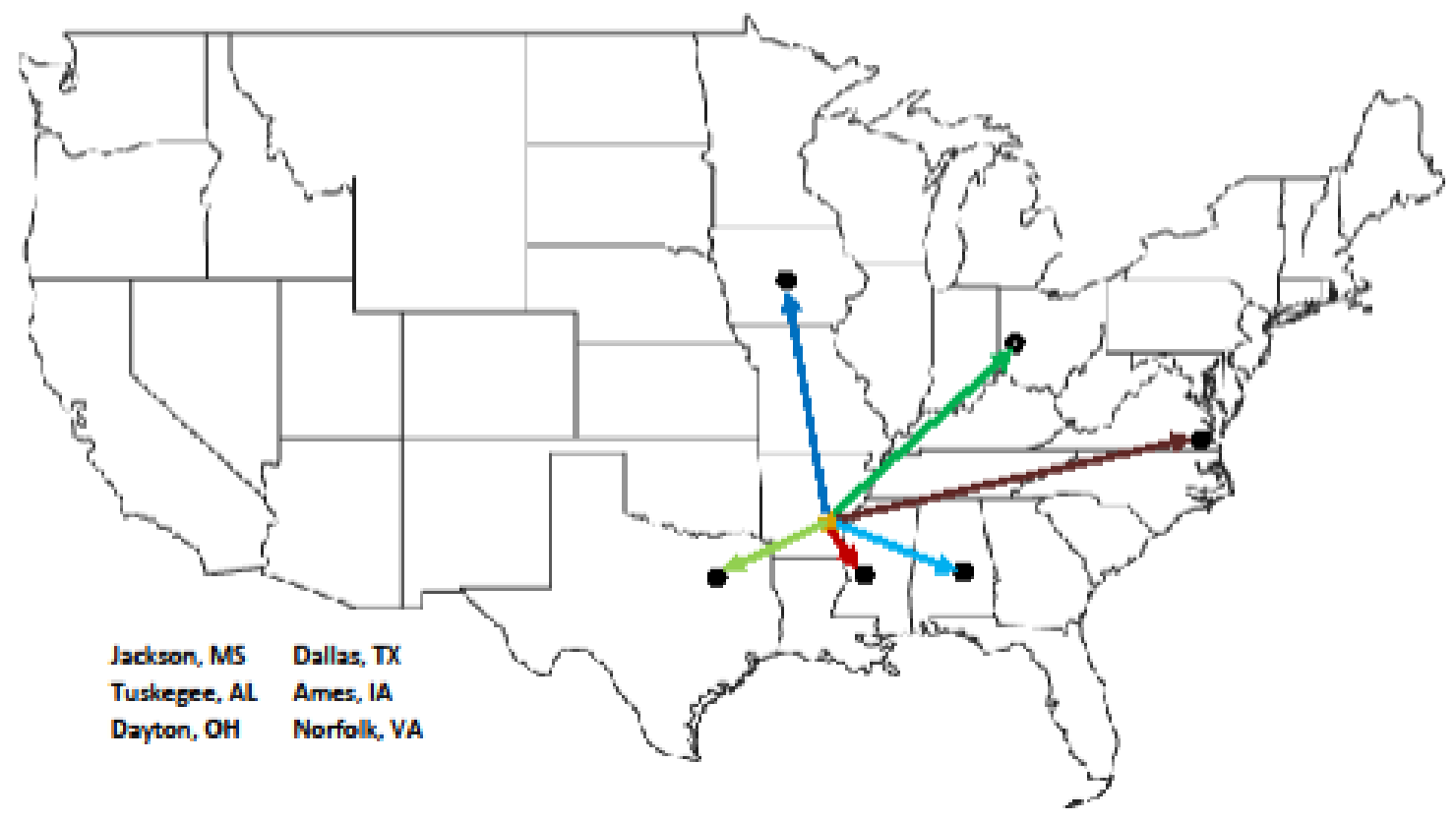

Figure 1. Participants from Pine Bluff, Arkansas, and their current locations.

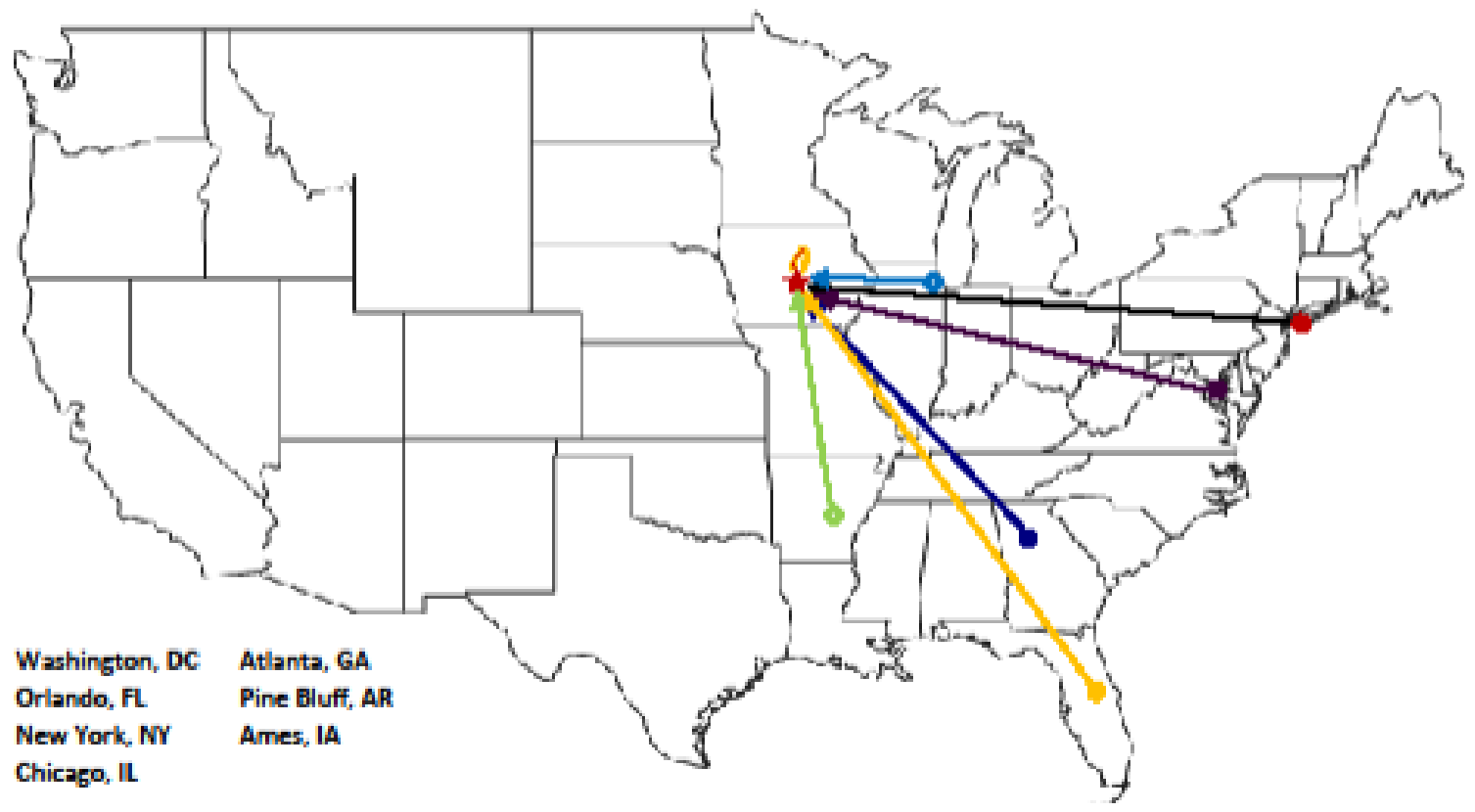

Figure 2. Hometowns of participants currently living in Iowa. 


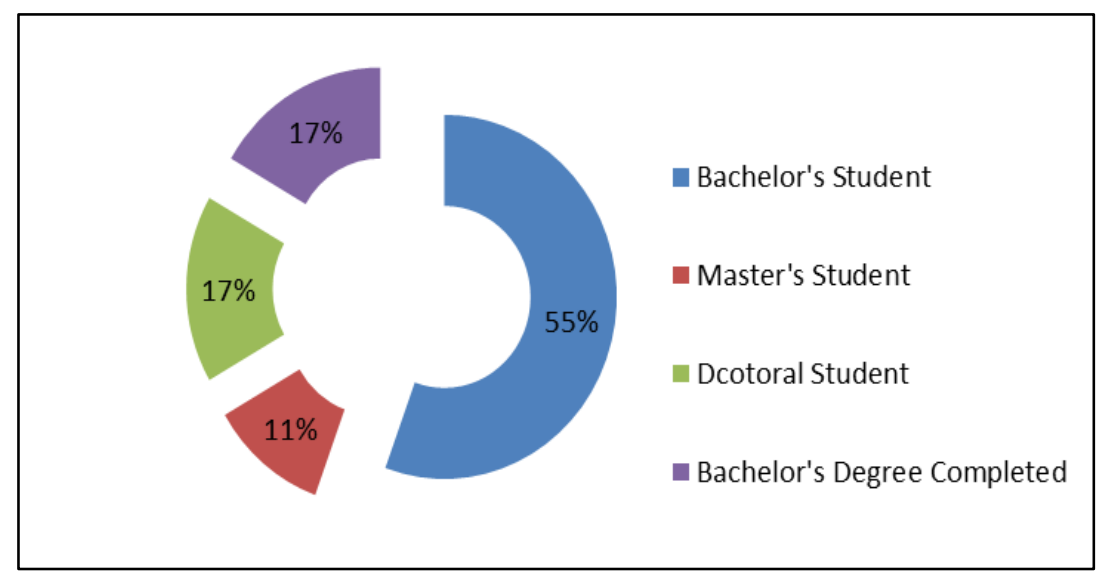

Figure 3. Educational background, by percentage, of the African American women studied.

\section{Thematic Analysis Among Major Topic Findings}

The results and discussion chapter is organized around major themes from participants' responses to the qualitative questions asked during the interview. In addition, each quote from participants that helps illustrate key themes includes the participant's pseudonym and age to provide an age perspective. The major themes are as follows:

A. Memory: First time using, wearing and buying of cosmetics.

Subthemes:

(1) Mother's acceptance: Receiving mother's approval before and while experimenting with makeup.

(2) Significant other provided training in use of cosmetics.

B. Shopping experience: Ranges from pleasant to hit-or-miss experience when shopping for cosmetics. 
Subthemes:

(1) Adapting to location: Settle for cosmetics products available in current location.

(2) Frustration or annoyance at having to travel far to purchase desired cosmetics brands.

C. Self-enhancement: The use of cosmetics makes individuals feel good about themselves and enhances self-confidence.

Subthemes:

(1) Putting the icing on the cake: The use of cosmetics completes their outward appearance.

(2) Self-Confidence: The use of cosmetics enhances personal beauty.

(3) Wearing cosmetics is fun: Use cosmetics to have a different look.

D. Brand preference: The degree to which a consumer prefers products of one brand over another product/brand.

E. Media source: A site where consumers visit and watch other consumers to get ideas on how to use and apply cosmetics.

Subthemes:

(1) YouTube: A popular site to find new ideas about cosmetic products.

(2) Excluded images of African American women: The cosmetics ads did not represent all complexions of African American women.

\section{Memories of First Use and Early Experiences}

Each participant was asked to describe her first memory of selecting, buying, and wearing cosmetics. This question evoked a variety of responses. The participants talked 
about what got them to wear makeup in the first place and their trials and errors of using cosmetics.

The memories themes reflect answers to questions asked directly by the interviewer and not themes that emerged from the data independently. In contrast, the other themes more independently emerged from respondents.

First time wearing cosmetics. The participants' descriptions of their memory of first using cosmetics usually included remembering characteristics of themselves. Kelly (23), a native of Pine Bluff, AR, and currently residing in Ohio, had no problem giving vivid details of her first time wearing cosmetics. She said, "I was in the eighth grade and my two sisters introduced me into the product line M.A.C. . . . I really didn't know too much about it, but I was at the age where you wanted to start wearing makeup." She continued:

not to go like too drastic but start wearing a little color ... scratch off the CarMex (lip balm) and the lip gloss. So . . that's when they first introduced me into lip gloss. We kept it very basic. It was like . . a neutral brown color. Amber (22), a native of Arkansas and currently a graduate student was also pulled into makeup use by others, but by a team rather than by family members:

Well, I remember . . . entering into my sophomore year of high school, so 10th grade. That's freshman year for us. That's when I got on the dance team and cheerleading team, and they told us we had to wear weave and we had to wear makeup, and I was like, "Nuhuh. I got my own hair [laughs]. I don't want to wear that." But . . you know my mom took me in and taught me what looks right and what doesn't look right. And of course they chose the hairstyles for us. But I got accustomed to wearing different things. So it was okay. It was just a shock! 
Solange (21), a senior at the University of Arkansas at Pine Bluff, was more selfmotivated to begin using cosmetics. She stated:

Okay well, when I first started wearing cosmetics, I started wearing eye shadow. I bought my first pallet from Claire's, and it was probably like $\$ 3.50$ or something like that. I just wore it to my games in junior high and stuff like that.

For Fawn (21), a junior at ISU, and Britton (22), a senior at ISU, their memory of first using cosmetics was that they had always wanted to dibble and dabble in makeup.

Out of all the women interviewed Audrey's (24) recounting of her first memories was completely different from the others. Audrey, who came from White Plains, NY, and was now a doctoral student in Iowa, replied:

My first cosmetic was nail polish. My mother took me for my first manicure and I was so excited! I picked out this blue color, and the reason that I remember this so vividly is because she talks about it. She was just so appalled that I wanted blue. It was a baby blue and the lady put a butterfly on it and I loved it! I paint my nails all the time [and] that is the main cosmetic that I use. I didn't start using makeup till I was in college. I only wore makeup in high school for prom.

Many of the participants began to wear cosmetics between the 8th and 10th grades in school and looked to their mothers for help, guidance, or an inspiration to wear makeup once they got older. None of the participants had any bad memories of trying cosmetics during their child hood.

Mother's acceptance. Many of the participants discussed how important it was to get their mother's approval before and while experimenting with different makeup pallets and foundations when they were growing up. Participants also reminisced about how their 
mothers used to apply their makeup and how they longed to wear makeup like their mothers did. Mothers clearly served as role models for makeup use and were often directly involved in socializing and training their daughters to use makeup. Hannah (22), a senior at the University of Arkansas Pine Bluff reflected:

I used to wear my mother's makeup, and ever since I was little I wanted to wear makeup. Because I used to see the way my mother put on her makeup and how pretty she would be, when she put on makeup.

Most participants believed that having parental influence helped them throughout their years of experimenting with different cosmetics products. However, one participant, Logan (22), a senior from the University of Arkansas at Pine Bluff, when reflecting on how her mother responded toward her wearing makeup, said she felt the need to develop her own identity and rebelled by wearing cosmetics early. She declared:

I just started wearing eyeliner and mascara. And I was actually sneaking doing it [laughs]!. Because my Momma, she wouldn't let me wear it at that age. But I would always put it on as soon as I got to school. And so you know one day I just caught slipping [laughs loudly], and she was like, "But you put it on good," so my mom started teaching how to put on makeup.

As Logan mentioned above, participants reported that their mothers became more accepting of makeup as they realized that one day their daughters would want to wear cosmetics. Some participants realized that acceptance once their mother took them to cosmetics counters. Natasha (23), a school teacher, said, "So for my 16th birthday my mom took me to Dillard's and we bought the whole like foundation, lip gloss, eye shadow, blush; we did the whole nine yards." 
With a somewhat similar response, Kylie (20), a junior from Tuskegee University, responded:

I couldn't start wearing makeup 'til I was 16. And my grandmother and mother took me to Dillard's, and they did a facial, and they showed me . . .which foundation I should wear and what eyeliner went with my skin tone. And I went with Estee Lauder so mostly they did it, and they wrote it down, and they told me what to buy. They really guided me into helping me learn what makeup is for me.

Each participant discussed how as a young girl she wanted to experiment with makeup but was not old enough to apply makeup on her face until a certain age. With acceptance from their mother, their mothers' attitudes become more relaxed about wearing makeup, and the daughters began to practice with different makeup products.

\section{Shopping Experience}

When I asked the participants about their experiences when shopping for makeup, I received a variety of responses. A few said they did not have difficulties finding their makeup and that, with the help of others such as the makeup artists at cosmetics counters, it was really easy finding and selecting a product that worked well with their skin. On the other hand, some of the women felt that their experience shopping was unsatisfying because finding products to match their skin complexion was very difficult at local stores. Some in both states felt the need to travel from their local city to find the right cosmetics products to be completely satisfied.

Natasha (23) said that she had good experiences when she went shopping for makeup during the week. She also enjoyed it when someone could actually help her through the process of selecting the products, because she did not shop for makeup frequently. The only 
time she had had a good experiences is when she found someone who could help her shop for what she actually needed.

Kylie (20) said the way she felt at the time determined her experience while shopping for cosmetics. She explained that she feels like she has to actually know what she is shopping for to have a good experience. She said, "My experiences are anywhere from good to bad. . . . It just depends on how I'm feeling and what I'm specifically looking for. When I'm specifically looking for things it's really good because I kind of know what I want." For some African American women, attempting to find the right product can be a grueling task. However, shopping for makeup came easily to Kelly (23), who had personal assistance through a friend:

A good friend of mine worked at the counter and she had done my makeup from prom; she's done it for debutante, and any like special occasion she's done it, and she's African American as well so I didn't have a problem! And everyone is not ... fortunate to know someone personally at a counter, just even knowing a makeup artist, so by her being African American, when I need something I strictly deal with her ... someone [who] knows ethnic skin. And so if I need something or if I'm out of town I will call her and get her opinion. She helps me match up my lip gloss or my eye shadow, because when [you have] different skin tones, you need to know what color insinuates, so having a good person or knowing someone is the key.

Kelly (23) believed that every makeup artist at the makeup counter should be knowledgeable about ethnic skin coloring, as should African American women themselves. Earlier in the interview Kelly suggested that, from a cosmetics standpoint and the way African American 
women do their hair and makeup, consultants should be informative about ethnic skin before they start working with the customer.

Kelly (23) was very confident in saying that she worked with one only particular makeup artist who's African American, because this makeup artist already knew her skin tone and what type of makeup is appropriate on her skin. In the following subcategories I touch on ways the African American women had hard times choosing purchasable makeup that matched their skin complexion and, later, how this affected their perception on where to purchase cosmetics products.

For many of the African American women, finding makeup to match their skin tone is not always an easy task. Many of this study's participants believed that their skin tone or pigments for makeup are rarely catered to, which made the selection process of finding that perfect foundation a little challenging. Ebony (29), a doctoral student from Washington, DC, was a little hesitant in her response, replying:

I think sometimes when it comes to picking out foundations; I kind of have a hard time matching the correct color of my complexion. So a lot of times you end up, with a color that not quite right . . then when you go to take pictures it's like, "Why does my face look like Casper the friendly ghost [laughs] and the rest of my body is a different color? [laughs]," and that's often a problem. I think the people, the cosmetologist, or whoever is employed to sell you the products, they try to find the best fit, but it doesn't always work.

Sybil (27) a doctoral student from Florida responded to the question with:

I don't have good experiences because I can't ever find what I am looking for and especially complexion-wise. When I am trying to match foundation, it is a bore for 
me. When it matches it is too greasy. Foundation is a big issue. When I find something that I like I don't get anything else.

During the interview Kellen (23), a senior from ISU, explained that she grew up in a White community. She described her experience as hopeless because she did not have the right assistance when it came to finding the right cosmetics products. She then told me that she was adopted and was not born in the United States, and finding cosmetics products in Iowa had been difficult:

When I started it was horrible because I didn't know what I was doing, and my mom is White and she didn't know what she was doing, and she was no help. But I just guessed and used a tester bottle. When I went to the mall at the beauty counter . . they matched me up.

Rachel (23), a senior at the University of Arkansas at Pine Bluff responded with:

Shopping for makeup was pretty much ... hit or miss. . . It was like a guessing game. Go into Wal-Mart pick something you think is your shade but when [you] get home, being that you can't try it on, you can't see what it really look like in the store. And you can't try it on there. When you get home it's a hit or miss. When [you] get home it's too red, or it's too light ... . even when you go to a different brand. For instance, Clinique or other brands that aren't specific for women of color, it's either too light or too red for your skin. And they try to match you as much as possible, but it's either it will break you out or it's not your shade. But when you find that one you know, that's it!

Rachel (23) did not just talk about selecting a foundation that would work well with her skin; she described the feeling of frustration when shopping for cosmetics. However, she 
did feel that most cosmetics products are not made for African American women, and whether or not the cosmetics appeal to her, most products would cause her skin to break out or were not available in a her complexion. With a smile on her face, she was happy to say that when someone finds the right product they definitely will know.

Statements such as these were very common from the participants throughout the interviews, indicating participants felt that looking for makeup to match their skin complexion was a hassle and eventually became frustrating, because most makeup products are too light or too red and, although some shades would enhance their natural beauty, others would leave their skin looking ashy, pale, or chalky. But in addition to just finding the right color, it was important to them to find foundation and other makeup products that worked well with their skin tone. As described by many participants, there were feelings of inadequacy because they never could find what they were looking for when shopping for cosmetics.

Adapting to location. During the interviews, the women in the study who were not originally from Ames mentioned their experience shopping for makeup at the local stores. Participants were concerned as to why the stores hardly catered to African American women, even though there are African American women who live in Ames. The responses as to why shopping in Ames was difficult were interesting. Most of the participants gave opinions about the selection and why they had to travel outside the city to get the cosmetics products they needed.

When I asked Kellen (23) about her experience shopping for makeup in Ames, she replied: 
I didn't really shop. I just jumped into it when my friends did. It was kinda, "Go for it," and if didn't work you just go back to the store and get a different one. Just keep going until you figure out what's good for you. As far as mascara, I look for the look that it will give me between length and fullness.

Later in the interview, when I asked Kellen (23) if she ever had any difficulties finding a certain brand, she replied, "Yes! In the middle of Iowa you won't get a whole brand of skin tones."

Britton (22), a senior at ISU, also expressed that finding cosmetics was difficult because of her location. She commented:

Well, my experience is a trial and error because of my location, because there aren't a lot of products in Iowa that are for African American women. You just have to try and see if it is your color and your skin tone.

When I asked Ebony (29) where she shops for her makeup, she responded:

Not in Iowa! [laughs] Generally because I like to buy like M.A.C. products and they like to sell it at Macy's.... I generally wait 'til I go home to [the] DC area and go to Macy's . . . or to Chicago or something because they don't have Macy's here.

Many participants felt the same way, wanting the local stores in Ames to carry a variety of shades for African Americans with darker skin complexions. Indeed, due to their location, the women felt that they had to settle for cosmetics products the local stores carried if they could not travel out of town to pick up the makeup that matched their skin complexion. This often put them in a situation in which they ended up traveling a distance to purchase the right cosmetics products that complemented their skin tones. The M.A.C. brand was sold at a department store in the larger urban area of Des Moines about 35 miles away, 
but several of the women living in Ames did not know about that one place of availability of their favorite brand in the middle of the state and may have had difficulty getting to the nearby city if they did not own a car or did not have the time to travel. The low proportion of women of color in the state population very likely encouraged the assumption that looking further in Iowa for appropriate products was futile. In contrast, the participants who resided in Pine Bluff did not have any problem adapting to their location, due to the fact that retailers in that Southern town offer many cosmetics brands that feature diverse color ranges to select from compared to retailers located in Iowa.

\section{Self-Enhancement}

Participants unanimously expressed that they used cosmetics products, and they described how cosmetics played a role in their lives. One of the questions asked at the beginning of the interview was the ways in which cosmetics enhanced their beauty. This question evoked several different responses from the interviewees, identifying their experience with cosmetics and what it meant, as a Black woman, to wear cosmetics.

Putting the icing on the cake. Many of the participants in this study felt more confident going to work, school, or running a few errands with at least some amount of makeup on. Each had a different outlook on how cosmetics enhanced their beauty. Although cosmetics usage ranged from a light application of mascara or lip gloss to fullface, complete with foundation, powder, concealer, blush, eyeliner, eye shadow, eye lashes, and some coats of lipstick, the volume of makeup that made each of the women feel confident differed. Fawn (21) aimed for a dramatic, noticeable look: 
I love it! I love anything beautified. I love big hair and standing out and when you walk in the room heads turn and people ask, "Who is that?" Makeup and cosmetics help you to do that. So I love it and thank the Lord for whoever started it. I am a fan. Logan (22) enjoyed versatility:

Personally I just like what it can do period! Just the different looks you could get out of it. It's something all the time. Like with the colors and stuff. It's just honestly the way you put it on too, that can actually just make your face bright. I don't know. It's just the way you put it on.

For some of the women, cosmetics meant a lot to their appearance and completely defined their personal appearance. Others preferred a very natural look. Kelly (23), who was currently working and living in Dayton, $\mathrm{OH}$, believed that makeup added extra enhancement to everyone's appearance:

I would say it puts the icing on the cake! Because this is how I see things [as she placed her hands together pointing at me]. When you have that suit on or that dress ... I don't care how beautiful you are. You need just that extra glow.

Kelly indicated that she felt that wearing cosmetics could do no wrong to anyone. She explained that, as an African American woman, it did not take much for her to look good; she later added that women do not have to look like a clown when applying their makeup. Kelly gave examples, such as that using foundations and translucent powder left her skin flawless. She later responded with "I strongly stand strong in [that] I do not care how beautiful your skin is, makeup is just something that enhances your natural beauty." Kelly mentioned that, as an African American woman, skin care is really important to her. Among the participants 
interviewed, she was probably the one who most extensively articulated her feelings toward cosmetics:

For me, I take it like from a different surface level. I think about the dermatology aspect of it. The skin care ritual, it's like with African American women, we are more prone to acne and ... most of us have oily skin. So a good regimen for me, if I don't even think about makeup, I think about the healthy skin care aspects, from washing, conditioning, and toning and moisturizing. That's like a big deal for me. In the morning like when I get up, it takes me like 20 minutes. I have to wash my face, then I tone it with witch hazel, and I'm doing like a mask and a moisturizer, and so I look at that from the skincare side. And . . I would even say from a diet, just what I'm taking in, because I think that has an important role as to the longevity of my skin care as well.

However, during the interview, when I asked Hannah (22) why she wore cosmetics she said, "To enhance myself. I think I'm pretty without it, but I think it enhances my features that I like about myself." Although some African American women can obtain flawless, beautiful-looking skin by practicing basic skin care routines, most African American women tend to have a combination of skin care issues. Although each woman is different, of course, many African Americans have oily, dry, or uneven skin tones, so before finding the right skin care product, one has to define what type of skin she has. Indeed, most participants who had complexion issues used makeup that helped disguise their problem areas; some used concealers to hide dark under eye circles or blemishes.

Evidence for the development of self-completion relating to their appearance was found in the responses. For instance, Rachel (23) felt that some days, when she got up in the 
morning, her eyes were really puffy. She commented, "If I didn't have concealer, oh my goodness, I would be a mess, concealer ... I love [it] so much. It is my best friend. Really!" According to Wicklund and Gollwitzer (1982), an individual who feels less complete is more likely to be insecure. Rachel revealed that she felt insecure when she did not apply concealer when she was about to start her day of school or running errands.

Self-confidence. There were a variety of reasons why participants believed the use of cosmetics enhanced their beauty. When I asked Kylie (20) in what way she felt that cosmetics enhanced her beauty, she responded, "I really think it gives me the extra confidence. I like you know . . the way I step out. I love the way it makes me feel. It's like it completes me. It just seals the deal with whole outfit." Natasha (23) had a similar response: "It just makes me look all put together. It completes the package that I'm trying to present to people at the end of the day." She then added that she wanted to look presentable. Rachel (23) indicated that wearing makeup gives her an inner glow. She said that wearing makeup actually showed what she already had, and she did not have to put on too much. She added, "I just put on enough to cover, and when I say enhance, enhance what I already have whether [it be] my eyes with mascara, just give you that extra pop!” Kylie (20) also told me that wearing makeup gave her that extra glow. She commented that she believed that wearing makeup was an extra confidence booster. She then said that, when someone complimented her on her makeup or lipstick, it made her feel good about herself.

For some women, wearing makeup can affect the way they view themselves and also how others view them. Ebony's (29) response was different from those of the other women I interviewed. She stated: 
Umm yes, I feel like as a woman [if] you don't wear it, you're most likely looked at as being unfeminine. You know like ... it helps you have a feminine appearance and to be more attractive to the opposite sex.

Ebony used makeup to feel more feminine, possibly connecting femininity with being attractive to men. Evidence has shown that many women use makeup to meet standards and gain attention from the opposite sex (Kelson et al., 1990; Scott, 2007).

Hannah's (22) description of why she wore makeup and why she believed that cosmetics were related to her self-identity and self-confidence was:

Once you wear [makeup] so much you feel naked without certain stuff. Like you don't have to have a full face of makeup. You feel like you might need lip gloss or something. Because you feel naked without it. And you don't feel like yourself. Although many of the participants voiced that wearing makeup was not in any way related to their self-esteem or self-confidence, Logan (22) expressed that she did not have to wear makeup; it was just something that she liked to do. She then said that she liked to portray a different "story" when she applied her makeup. She was really quick to say that wearing makeup did not help with self-esteem because, with or without makeup, she was still that same person. When I asked Amber (22) the same question she replied:

I feel like I don't need cosmetics. But it's always an enhancement to just make yourself feel a little bit more dressed up. Like if you are going somewhere. You know you add a little makeup just to add a little radiance to your face or whatever. That's the only thing. But I don't think everyone needs makeup. But I think we use it as an enhancement that's all. 
When I asked Natasha (23) if she liked to wear cosmetics and why, she replied, "I do because it completes. At the end of the day it completes me. But I don't like it's a have-to thing. I don't have to wear makeup to look beautiful." Similar to Natasha, Britton (22) said "Maybe on scale of 1 to 100 it's a 20, because I think I'm pretty without makeup but I feel more complete with it on."

Wearing cosmetics is fun. Many participants revealed that generally they regarded wearing makeup as a female or feminine thing to do. With all of the different colors, textures, patterns, and brushes involved, playing around with makeup can simply be seen as a fun activity, but some women believed that when they applied their makeup and got a complete different look, it could be considered art. Kelly (23) commented:

I will say that's where you have your personal touch. Once you learn how to put it on you can have your night-time look and you can have your everyday look. You can have your going-out look and so once you get the gist of it, you can have your own little ritual. You can change your lip gloss, you can change your lipstick, you change your eye shadow. And that's the beauty of it!

Kelly (23) continued, "Someone can teach you how to do it, but then you want to put your particular touch it to. So [it's] yours, [that's] your signature." I then asked Kelly what her signature look was, and she replied, "I will say with me, I'm very funky. I never keep the same hair style. My lip gloss, my hair color is always changing." She then told me that she loved wearing bright pinks, bright reds, and purple lipsticks, and if she needed to tone down and have a more settled look, she usually applied her brown or gold eye shadow and brown lip gloss. Those earth-tone colors were items that she carried with her every day. Rachel (23) had a similar point of view: 
Umm, I think it's about having fun when you can go outside of the box. Not caring about what other people think ... playing with color ... not just sticking to neutral tones. . . seeing what is out there, trying different pots ... different looks ... from the night look to the day-time look ... or even like playing with different patterns and not just doing the simple build. ... I guess you can call it, just like doing the cheetah print on one side and like stars on another side. Just playing with and going outside of the box makes cosmetics and actually doing makeup ... fun.

When Audrey (24) was asked why she wore makeup, she responded, "I do it for me, It's fun and I like painting; it feels like I'm painting." She then added, "The whole application process, it's like painting your face. I try new things. It's an art project to me

and you have to blend it." Hannah expressed that "it's fun to put on makeup and see yourself look different." The women interviewed wore cosmetics because it was fun to look different from time to time.

\section{Brand Preference}

During the interview, when participants were asked what their favorite brand of cosmetics makeup to wear was, many of the participants expressed their love for the M.A.C. cosmetics line. Most of the women agreed that M.A.C. cosmetics have rich pigmented lipsticks, its foundation is oil free, and there are extensive colors from which to choose. The women also said that M.A.C. cosmetics are high quality products and long-lasting compared to drugstore or less expensive makeup. The women felt that shopping for M.A.C. cosmetics was a hedonic, multisensory experience that provided fun, pleasure, and excitement (Dhar $\&$ Wertenbroch, 2000). 
The discussion with participants about cosmetics brand preference revealed how much the women loved M.A.C. cosmetics. They loved to see the new collections' advertisements online so that they could be up-to-date on all of the latest M.A.C. cosmetics and stores. They loved that the company portrays glam and couture dramatic looks, great customer service, and most of all, they loved that M.A.C. had a varied selection of shades, from light to dark, for women of all colors. Celebrities such as Lady Gaga, Nicki Minaj and Rihanna, all landed deals with M.A.C., adding perhaps further glamor to the brand.

Solange (21) indicated that M.A.C. was the only brand of makeup that did not make her break out and that M.A.C. foundation complemented her skin tone. Amber's (22) response was similar:

I love M.A.C., and I think because I have darker skin, and it works well with me. I have oily skin as well. And I wear like powder [that] doesn't just really look like I have so much caked up makeup. So I really love M.A.C. products, and I use their . . Studio Fix which is their powder and I use their lip gloss. Because it doesn't break my skin out so I like that product.

With a similar response, Kelly (23) stated:

My brand preference is M.A.C. I've been wearing that for about eight years now. Like I said my sisters introduced me [to it]. I use their concealer, their foundation, the liquid and the powder form. I use their mascara, lipsticks, their lip gloss, so I'm pretty comfortable to say I use their entire line. Plus . . . their brushes, the one thing I like is that they all are oil-free products.

Kelly went on to say that she had very oily skin. She also commented that M.A.C. had an AIDS fund and a small percentage of their funds went toward the AIDS foundation. She 
added that when she has six empty containers she can get a free lipstick. She was pleased to say "they have a variety as far as their foundations for African American women."

VIVA GLAM is the first line of lip glosses and lipsticks that was created to help raise money for awareness for AIDS. Every cent of the sale price the customer spends goes to help individuals living with HIV/AIDS around the world. The M.A.C. AIDS fund is a nonprofit organization that was created in 1994 to help and support individuals who are living with HIV/AIDS nationwide. The M.A.C. AIDS fund also donates funds to communities that offer services and help to prevent HIV/AIDS through educational programs (M.A.C. AIDS Fund, n.d.).

M.A.C. cosmetics has raised over \$224 million dollars to date from the VIVA GLAM HIV/AIDS campaign (M.A.C. AIDS Fund, n.d.). Moreover, according to (Sampey, 2012), the African American community has more brand loyalty than the European American community. It has been quantified that African American consumers are more passionate about brands when African Americans find a product that works for them. Also African Americans are eager to share and express their satisfaction about products with family and friends, as well as urge others to buy or use their product selection (Sampey, 2012). Because of their brand loyalty and appreciation of altruism on the part of the brand, many of the women spent more money on quality M.A.C. cosmetics products.

Kayla (22), a senior from the University of Arkansas, said that M.A.C. products are long-lasting and that she had her foundation for about a year, because she did not have to use much of it. When I asked Rachel (23) to tell me about her favorite cosmetics products, she replied: 
My favorite . . cosmetics line is M.A.C. I’ve worn that specific brand since my ... 9th grade year in grade school. That has been my favorite! It always worked for me and when I tell you [shaking her head] that particular brand fits my skin perfectly! I love it, love it, love it! From the lip gloss to the lipstick, to the foundation . . . and the skin care line. That works for me and I think it will forever work for me.

Ebony (29) indicated what her favorite cosmetics products were and broke them down as to why she wore those certain products. She stated, "When it comes to any of my foundational makeup, I always use M.A.C.” Later in the interview, when asked what drew her to wearing M.A.C. cosmetics, she replied:

I think it started in high school . . No it probably was in high school or undergrad . . . because it became kind of big! And everyone was like, "Ooh, M.A.C. is the thing to do. You know you wear M.A.C. lip gloss and all these [laughs] these other M.A.C. products" and it was the cool thing. So I was like, "Ooh, let me try out M.A.C." Ebony (29) went on to say she was aware of other Black cosmetics product lines but that their products were not cool enough and "just kind of dull or boring." But most importantly she loved how the M.A.C. company drew her to their products. She said that with M.A.C. you know they really attract you because the people that are selling it to you are outrageous. Well, they used to; now they kind of toned some stuff down. They used to have like the really long eyelashes on top of the fact that their colors were so vibrant and you're like, “Ooh, I want that," you know [laughs], you know I want to look like that. So, but that's what attracted me to M.A.C. for a cosmetic line. However, when Natasha (23) was asked what her brand preference was, she explained that she was transitioning: "It was Fashion Fair, but I think I'm going to go over to 
like M.A.C. I think I'm going try M.A.C. for a little bit to see how that works." When asked why she wanted to transition to M.A.C. from Fashion Fair she said,

That's a good question! I think with Fashion Fair it's hard to find Fashion Fair. But everybody has M.A.C. Like you can go to an outlet store for M.A.C., and they have it. But it's kind of hard to find Fashion Fair. I think they're actually closing down that brand. So ... that's why I'm in transition to M.A.C.

M.A.C., among other brands, carries a vast range of shades in products like foundation, eye shadow, blush, eye liner, mascara, and lipstick. African American women have skin tones in a broad range of the color spectrum. The M.A.C. brand allows African American women to shop based on their specific skin tones instead of dividing the products along color lines. Many of the participants loved M.A.C. products because they believe their skin is included and they can enjoy feeling beautiful. Weitz (2001) defined "power" as having the ability to control or influence others to reach desired goals. Some African American women discovered the power of cosmetics by using cosmetics to achieve a flawless look or change their appearance from day to night at any given time while using cosmetics. However, using the M.A.C. brand helps the needs of African American women and empowers them to take control of their own personal beauty. Moreover, African American women put forth an effort to put their idealized face forward, but took some personal control in deciding features and characteristics of that ideal face.

\section{Media Sources}

There were a variety of responses surrounding the issues of cosmetics and searching for guidance on a particular look. The media played a part for the participants in finding this information. Every participant was aware of the various forms of media such as magazines, 
television, and the Internet. The majority of the women did not look at magazines or the Internet for cosmetics on a regular basis but did refer to them on occasion. The women were varied as to how much they believed that media images had impacted how they felt about their own makeup and their motivation to engage in trying new looks. More specifically, participants expressed how watching YouTube videos helped illustrate for them classic looks, such as the "smoky eye," and in seeking new makeup techniques and new products recommended for African American women.

YouTube. Out of all the topics discussed during the interviews, the participants were most passionate about finding new ideas for makeup on YouTube. The women had a lot to say about how watching YouTube tutorials helped them prepare for fun nights out with friends and helped them with new makeup looks and creating unique looks using makeup, hair, fashion, and beauty products. Fawn (21) stated that she received compliments on her eye shadow every time she put on her makeup. When asked what type of compliments she received from others, she replied, "I like your makeup!" and she then said, "I tell them ... YouTube! [laughs].” Fawn (21) went on to say, "I love YouTube; I could be on there all day. I watch for makeup techniques, from how to make my face thinner and hair gurus. I just really like it."

Fawn's statement echoed what many of the participants had to say about watching YouTube tutorials about makeup. Rachel (23) explained that she watched YouTube tutorials on natural hair and noticed that her beauty guru had more tutorials about makeup than she did about natural hair. Rachel (23) stated:

I started going over her tutorials and I was like, "Oh my God! This is like a break! Oh my God this is it!” And she was showing step-by-step how to use the primer, or 
how to fill in your eyebrows perfectly. Or how to . . make your eye brows look like they have been waxed and they haven't been waxed. It's just so many tricks and guidelines. So many different things you can do just by watching a tutorial online and it's pretty amazing!

Other participants acknowledged they also watched YouTube videos for makeup and hair ideas. Logan (22) said that on YouTube she had found a woman who did tutorials on hair and makeup and she watched her a lot "especially when it comes to how to apply lipstick. Because sometimes we just put it on then that's that." She believed that watching YouTube would help her learn new ways to apply different lipsticks and lip liners, which would transform her look from boring to bold. Many of the participants also believed looking at YouTube was good, but it was nothing like someone actually showing what to do with the makeup and the correct way to apply the products.

When Kylie (20) was asked if she had ever looked at YouTube tutorials for makeup guidance, she said, “All the time! Pretty much once a week. I'm always looking at what way, something I can do different with my makeup. So I always look at YouTube." Natasha (23) replied to the question with a simple, "YES! YES!" When I asked her to explain and tell me more about why she looked at makeup tutorials, she said,

I think it was more for the eye shadow thing. I want to do something special. And then you know the shadowing. They call it shadowing and I like it. I think I pulled it off pretty well. It was very helpful.

Many of the participants watched YouTube makeup videos to learn how to do the smoky eye. Audrey (24) stated, "Yes, I have looked at YouTube for the smoky eye. I have big eyes and I think that it looks a little smaller or sleeker." With a similar response Linda 
(23), a master's student at ISU from Pine Bluff, Arkansas, said, "I look on YouTube for the eye makeup and the different colors and how to blend it in." Kayla (22) conveyed a similar response, stating that she watched YouTube tutorials, "especially for eye shadows, foundation everything!" when asked what she was aiming for when watching the videos. Earlier in the interview she explained that she was a dancer for the University of Arkansas at Pine Bluff and she watched the makeup tutorials "sometimes when it's for performance; I try to see how they keep it on. Especially for me, I sweat a lot, so I have to use like concealer. I put concealer under my eye shadow." Kayla learned from the tutorials that applying the concealer under her eye shadow would make her eye shadow last longer, which was helpful during her performances.

On the other hand, for Kelly (23), watching YouTube was not something she did a lot. She said that she had seen the YouTube tutorials that gave step-by-step instructions on how to fill in the eyebrows and do smoky eyes. She added, "They even have videos if you want to do the Kim Kardashian look or if you want the Nicki Minaj Barbie look." However Kelly (23) indicated that she liked to get her makeup ideas from other media sources. In Kelly's words,

Whether I'm watching Housewives of Atlanta or Beverly Hills, I like to get my ideas from there because I love the home décor; I like even from their fingernail polishes and just getting ideas — makeup ideas, hair style ideas, and even like the latest trends in fashion.

Participants recognized that the media had an impact in their lives and that, in general, the use of makeup has the need to alter one's physical appearance. Watching the beauty tutorials about product reviews helped the women know what was new to try out and 
taught them how to apply makeup or just try something new. Many of the women enjoyed watching the media sources to gain helpful tips, from an everyday look by adding color to their cheeks to finding new ways to express their mood and personality.

Excluded images of African American women. During their interviews, the women in the study mentioned that more African American women were needed in cosmetics advertisements. Many of the women were quick to point out that the images of the African American woman featured in most of the cosmetics ads did not represent all complexions of African American women. However, the women did feel that the images of African American women in cosmetics ads are getting better at bringing more attention on women of color.

Kelly (23) believed that African American women look unappealing in cosmetics ads, saying:

I will say it's getting better. But there's always room for improvement. Because even when I look at magazines or even commercials on TV, I mean let's just be real for a second. When I'm flipping through pages or even when I'm looking on the Internet. I see the Caucasian woman and I feel like she's dressed up to the "T," and then I see the African American women; I'm looking . . . I feel like they just put something on her, the makeup is tacky and their hair is messy.

Kelly continued, saying, “As an African American woman, I'm really not pleased; there's room for improvement." Audrey (24) had similar feelings; she did not like the way some cosmetics companies portrayed African American women:

I feel like most companies, Covergirl and L'Oreal has commercials. I think that they do a good job. I don't like the Beyoncé commercial with L'Oreal because . . . they let 
JLO go 100 percent Puerto Rican. And they had to say she was French, African American and Caucasian, and I don't know why Beyoncé can't just say I am African American 'cause she is. Like you're not French or Caucasian, all Black people are for that matter. I just feel that's the time that she could have said, "Yes, I am African American," and I don't know if she chose not to or L'Oreal chose not to, but I don't like it. In general they do a good job.

Many of the women brought up examples as to why the cosmetics ads need to improve to be able to generalize across more African American women. Logan (22) said, “Well, I believe companies like L’Oreal think that if they get someone as big as Beyoncé, then the rest of her fans will follow. But that's not necessarily true." However, Logan also believed that if the cosmetics company didn't "have the tone, the right tones for us. We [are] not going to follow."

Moreover, Ebony (29) believed that most cosmetics companies tried to wash out the complexion of women of color by lightening their skin complexion instead of portraying the women as African American women. She stated, "If that person is that complexion you need to portray them as self. Not try to wash them out in anyway." She said that "[I] always appreciate Queen Latifah; I think she is [a] beautiful woman. And she represents ... the African American women very well."

Kylie (20) believed that African American women were not represented well in advertisements and that Queen Latifah was the only African American woman she saw in ads. She said:

I definitely feel like we are not really represented in cosmetics. When it comes to advertisement of cosmetics. I think the only African American we really see is 
Queen Latifah. And I feel like it so much more than her. So many more shades of African American women. And I feel like, yes, there needs to be a change. You don't really see African American women being advertised for our makeup and there's so many things that they can show.

Kylie (20) firmly believed that more African American women were needed in future cosmetics ads and that having more women of color for cosmetics ads in the media was essential to the African American community. She also believed that the cosmetics industry should open its eyes and recognize the beauty of all shades of African American women.

A previous study conducted by Duke (2002) also showed that younger African American teen girls felt underrepresented and felt that mainstream popular magazines seemed to overlook and exclude minority girls throughout the magazines. Duke also found that African American girls purchased the magazines not to adopt or validate the dominant standards of beauty, but to analyze the magazine articles and feature content for relevance to themselves as African American girls. The African American teens mentioned that the clothing, cosmetics, and grooming products advertised or discussed in the magazines did not fit their preferences or needs of African American girls. Many of the African American teen girls had the notion that White dominance is normal and accepted through the mainstream of media, but did not passively accept that dominance, despite their purchase and consumption of some of that mainstream media. The women in this study also did not express acceptance that women with darker skin should be excluded or served in only limited ways by cosmetics retailers. 


\section{CHAPTER 5. SUMMARY AND CONCLUSION}

The purpose of this research was to understand why African American women use cosmetics products and how the use of cosmetics is related to their self-identity. This research afforded the opportunity to explore African America women's use of cosmetics products and gain an understanding of why African American women wear cosmetics and how the use of cosmetics plays a role in their lives. To date, little research has explored the topic of African American women and their attitudes toward cosmetics products in relation to their self-identity. This qualitative approach, utilizing semi-structured interviews with 18 participants, was used to explore the meanings of why African American women wear cosmetics as well as to understand their feelings, beliefs, and attitudes toward cosmetics products that work well for African American young women.

\section{Summary}

The purpose of this research was to gain understanding of African American women's use of cosmetics in relation to their self-identity as well as the meanings behind their use of wearing cosmetics. In-depth interviews were conducted for this qualitative study of a targeted sample of young adult African American women between the ages of 20 to 29 years who wear cosmetics. Although much research has been conducted on cosmetic surgery and on cosmetics use by European American consumers, little to no research has explored African American women using cosmetics relating to their self-identity. Thus, this study aimed to fill a gap in the literature regarding African American women's behaviors and concerns and beliefs about the use of cosmetics.

The present study employed a qualitative method approach. In-depth interviews were conducted with 18 African American women, 11 from Pine Bluff, Arkansas, and seven living 
in Ames, Iowa. Participants were selected through a snowball sampling to a limited extent in order to establish a level of trust. Most of the participants were invited to partake in the study through minority student and professional Black women networks. The interpretive analysis resulted in five main themes: (a) memory of first use of cosmetics, (b) shopping experiences, (c) self-enhancement, (d) brand preference, and (e) media sources.

\section{Memories}

During the interviews it was found that many of the women began wearing cosmetics at different periods in their lives. Many of the women expressed that they started to wear simple cosmetics, such lip gloss or nail polish, at a young age and that they enjoyed wearing those products. For some, wearing cosmetics began in the eighth grade around age 13 or 14; for others it was later, around the age of 16.

The women revealed that, while experimenting with cosmetics, they began to develop their daily makeup routines and also developed needs for must-have products and what is considered to be "essentials" when wearing cosmetics. Participants sought to wear cosmetics because they were in or moving into teen years, and their family members introduced them to wearing cosmetics.

Many participants remembered that their mothers helped them understand the use of cosmetics products by taking them to makeup counters to learn the proper way to wear makeup and the correct amount to apply. Participants understood that their mothers needed to approve their makeup before wearing it, but some felt the need to rebel against their mother because they wanted to find their own identity, setting the stage for future makeupwearing habits throughout the years as they became older. The participants engaged in the 
use of many cosmetics products at a young age and wanted to experiment with different products because their family members were wearing cosmetics.

\section{Shopping Experiences}

Shopping for cosmetics could be a hassle for some participants. It was found that participants had some difficulties finding the right foundation to match their skin complexion. Many participants believed that finding cosmetics was a hit-or-miss experience when it came to shopping for cosmetics in local stores such as Wal-Mart, Target, or drugstores. Participants believed that the local stores carried foundation or blush that was too reddish or too light, which would lead to their skin looking ashy, pale, or chalky. Many of the women with a darker skin complexion expressed how they had to mix foundations together from different cosmetics brands to formulate the proper shade of makeup for them because the search to find the right skin tone was problematic. However, the participants who shopped at makeup counters generally did not have as difficult a time finding the right cosmetics products because they were helped by a professional, trained makeup artist.

Many participants expressed that having someone help them select cosmetics products is a huge help when trying new products and matching the skin. Some participants expressed that it was very imperative that makeup artists need to be knowledgeable of skin of color, especially when it comes to the skin tones of African American women. However, participants from different parts of the country, who were living in Iowa temporarily to attend school, voiced that they had to adapt to the location. They faced distress in finding their correct shade of makeup due to the fact that the local stores carried fewer colors of foundations for African American women to match their skin tone and to work well with their skin without skin irritation. Furthermore, some of women felt they needed to travel to 
different locales to get the cosmetics products that would satisfy their beauty and aesthetic needs with cosmetics.

\section{Self-Enhancement}

For women, wearing cosmetics is a form of magic that can enhance their beauty. Many of the women in this study explained that applying cosmetics was needed to enhance their features. However, all the participants loved their own unique and special features when it came to their faces. For example, applying eye shadow could change their eyes to be more attractive and bold; applying lipstick could convert their ordinary lips into more luscious ones by defining the shape of the lip. All of the women expressed positive attitudes regarding the use and application of cosmetics, with many believing that cosmetics added an extra touch to their outfit or attire or to facial beauty which led to a sense of self-completion in how they defined themselves (Wicklund \& Gollwitzer, 1982).

The women expressed that wearing cosmetics added to their natural beauty, enhancing their already beautiful physical features. Products such as mascara might make their eyelashes pop. Cosmetics seemed to boost the women's self-confidence by enhancing their natural features, creating an inner glow that left them satisfied and complete. However, a few of the participants expressed that wearing cosmetics was not something they had to do to look and feel beautiful, but they enjoyed using cosmetics nevertheless.

Many of the women expressed how they like to get dressed up and enhance the features they already had. Also the women wore cosmetics to cover blemishes, acne scars, and uneven skin tone. Cosmetics can serve to hide physical reality and present an attractive or improved mask to the world. Tseelon (2012) proposed that masking has several motivations, which consist of the following: (a) mask: a self-consciousness maneuver of 
deception that enhances and calls attention to an individual's appearance of a necessary quality (e.g., adding cosmetics); (b) disguise: to impersonate, hide, or take a social role that will be seen as more desirable (e.g., hide flaws with cosmetics); (c) masquerade: individual or represented groups pretending to be someone they are not, that show a false outward appearance (not described by respondents in the study). In addition, Tseelon articulated that the philosophy of masking is based on personhood. The concept of personhood links masking as a conduct that hides realities and edits the truth of the self. One of the participants expressed that wearing cosmetics is very important in today's society to look, feel, and appear more feminine and to look more attractive to the opposite sex. The masking concept relates to Goffman's (1959) notion of presentation of the idealized self (i.e., feminine and attractive for women) to carry off a role effectively.

Some of the women indicated that they did not need to apply much makeup to look good. Moreover, it was found that the women expressed that they look good with or without cosmetics. However, when they were going to be around a lot of other people, the women wanted to look their best. Furthermore, the women expressed that wearing cosmetics was a form of art used to express and enhance their creativity and that using makeup and eye shadow enhanced their facial awareness. From the women's point of view, wearing cosmetics is a form of art with their face considered to be a blank canvas, and applying cosmetics products creates a picture that enhances their self-expression and builds confidence in their everyday life.

\section{Self-Confidence}

Many of the women believed that wearing cosmetics gave them extra confidence. Participants expressed that wearing cosmetics "completed the package" when they were fully 
dressed. The women specified that wearing cosmetics helped identify themselves as a woman, and cosmetics gave them a sense of worthiness (Schmitt \& Allik, 2005). Some women also indicated that wearing cosmetics gave them an inner glow when applying cosmetics that highlighted their facial features. Many of the participants believed that they did not need to wear cosmetics to feel pretty. However, psychological tension was revealed within the women saying they are pretty without wearing cosmetics but still wear it to feel positive about their appearance. Also, some of the women developed self-confidence when they received compliments from others on their makeup. Parker et al. (1995) found that African American women often receive positive compliments from friends and family when they are "looking good," which may enhance their feelings about the self.

The women also expressed that when they do not have on cosmetics they felt "naked" and unattractive. The "mask" of cosmetics helps them to face others. Some of the women may have a downward social comparison when they see other women wearing cosmetics and presenting an idealized physical attractiveness and beauty (Festinger, 1954). Many of the women expressed that they do not need to wear cosmetics to look beautiful, but cosmetics add an extra touch to appearance that bolsters their self-confidence. During the interview the researcher did not prompt the women to talk about self-comparisons with others, perhaps reducing discussion about that process. However, from the responses referencing media and dressing for social situations, it is apparent that the women were involved in social comparisons.

\section{Brand Preference}

Many of the women paid more for quality cosmetics products that performed better than less expensive brands. It was found that the participants loved to wear M.A.C. 
cosmetics. Many of the participants were elated to talk about their favorite brand, which they preferred because the company's products were available in many shades, tones, and pigments to choose from to fit their skin complexion. Most of all, the women loved to wear M.A.C. cosmetics because the company caters to African American women who have oily, dry, or mixed skin types. They also liked to wear M.A.C. cosmetics products because of the products' high quality and long-lasting wear on the skin compared to inexpensive brands at the local drugstores. The quality of the M.A.C. cosmetics was very important to these African American women; they expressed the notion of "you get what you pay for," and the M.A.C. cosmetics line completely filled their needs.

Many of the participants wore M.A.C. cosmetics because it was the only brand that did not cause those with sensitive skin to break out. It was also found that the participants had been wearing M.A.C. cosmetics since their middle school years and that they began to wear M.A.C. because it was a popular brand for African American women to wear. The participants felt that once they found a product that fit their skin complexion and worked well with their skin tone, they did not want to use the products of any other brand than M.A.C. Many of the women were aware of other cosmetics brands that catered to African American women; however, they believed that the products offered by the other brands did not stand out to them the way that the M.A.C. cosmetics line did. They adored the bold eye shadows and lipstick colors; the smoothed foundations; the lip gloss with the wide assortment of colors that shined on their lips, keeping the lips moist for so long that they would not be dry under any conditions. They also enjoyed the glamorous marketing approach for the brand and the creativity of the makeup artists at cosmetics counters selling M.A.C. 


\section{Media Sources}

One finding that emerged during the interviews was that the women enjoyed finding and watching YouTube tutorials featuring African American women demonstrating new tricks and techniques for how to apply their cosmetics. It was found that the women liked to view the makeup YouTube videos to help them prepare for nights out with friends or watched the makeup videos to practice a certain look. Many of the participants viewed the YouTube videos especially to learn new ways to improve doing the "smoky eye" with diverse colors of eye shadows. The women expressed that watching the tutorials was an easy way to learn how to apply cosmetics correctly. Actually seeing someone do the step-by-step routine and what to use when applying the makeup, including the correct way to use and recommendations for such things as makeup brushes, face cleaners, and new cosmetics products, was a big help. However, the women seemed to be actively involved with YouTube, finding African American women of their skin complexion online to learn new ways to apply cosmetics. The women would watch makeup tutorials every day to once a week to see what new products were out and how to apply them. According to (Sampey, 2012), African Americans are more socially networked, and $49.2 \%$ of African American consumers also use services such as YouTube more than European American consumers do. However, out of all the women interviewed, one participant did not watch YouTube, although she was aware of what the tutorials entailed.

In today's society, women can be greatly influenced by the media, for example, by following trends from celebrities on what's "in" or what not to wear. These celebrities have the power of showing their fashions through appearances in the media. The media can have a positive or negative effect on some women's perceptions of their own beauty (Jones \& 
Buckingham, 2005; Monro \& Huon, 2005; Pompper \& Koeing, 2004). In fact, one participant stated how she liked to watch the women from well-known reality television shows such as Real Housewives of Atlanta or Real Housewives of Beverly Hills.

Many of the women indicated that the media still have room for improvement but that the images of African American women are becoming more appealing in magazines and commercials. The participants believed that the media tends to show only show Queen Latifah Covergirl ads. Some of the participants commented that Queen Latifah is doing a great job representing the African American community and providing a diverse palette of foundations for African American women, but many expressed that there are so many more African American women's cosmetics brands that can represent different skin complexions than just Queen Latifah's cosmetics brand. Although the women felt that the media do not portray a lot of images of African American women, the women felt that the images of the African American models on commercials and television look thrown together or it looks like the African American women's skin has been lightened to fit the ideal standard of beauty.

Studies have shown that the media manipulates the standard of how women should look (Lynch, 2007). For example, some of the women expressed their feelings about the cosmetics brand L'Oreal and how the images of Beyoncé, who is an African American woman, have been deconstructed, white washed, and altered to a state of impossible human perfection. Her skin and hair are too light, which makes her look racially ambiguous. Many of the women enunciated that every African American woman is not light skinned nor are they all dark skinned, and more diversity in color needs to be featured in the media. In other words, they believed that the images in the media and cosmetics companies' literature should 
exemplify all skin tones of African American women and that it is essential to the African American culture. Finally, it was found that the media and cultural perspective did have an impact on these African American's use of cosmetics products and their clothing choices.

\section{Comparisons Across Regions}

In the present study, participants from Pine Bluff and some of the participants in Iowa expressed that finding cosmetics such as foundation to match their skin complexion could be difficult if they are shopping at local discount stores such as Wal-Mart or Target. Participants from Pine Bluff expressed that the ability to find their correct shade was fairly easy if they used a cosmetics brand that carries a variety of foundation colors for African American women. However, each participant from Pine Bluff tried using other cosmetic brands from local stores but was more successful finding her correct shade of foundation at department store cosmetic counters than at local stores. However, due to the limited cosmetics products for African American women sold in the local stores in Iowa, the participants living in Iowa had a challenging time finding cosmetics to fit their skin complexion.

The limited availability of appropriate cosmetics for African Americans may be a reflection of the low percentage of diversity in the population of Ames, IA, compared to Pine Bluff, AR. Stores in Ames may not recognize that they are missing the needs of some consumers in the university community or may not be accustomed to or knowledgeable about how to cater to diversity in the area. Many of the participants expressed that cosmetics were hard to find in the Ames location. According to the U.S. Census, Ames, Iowa has a small percentage of African Americans residing in Ames (see Figure 4). In contrast, this can predict why fewer cosmetics are sold to dark skinned women residing in Ames compared to 
women in Pine Bluff, Arkansas, which is a predominantly Black community. Many of the participants from Iowa voiced that they did not like to drive out of town just to purchase cosmetics products, and they did not like that brands to select from were limited. Many of the participants in Iowa felt like they had to settle for products found through hit-or-miss shopping experiences (see Figure 5).

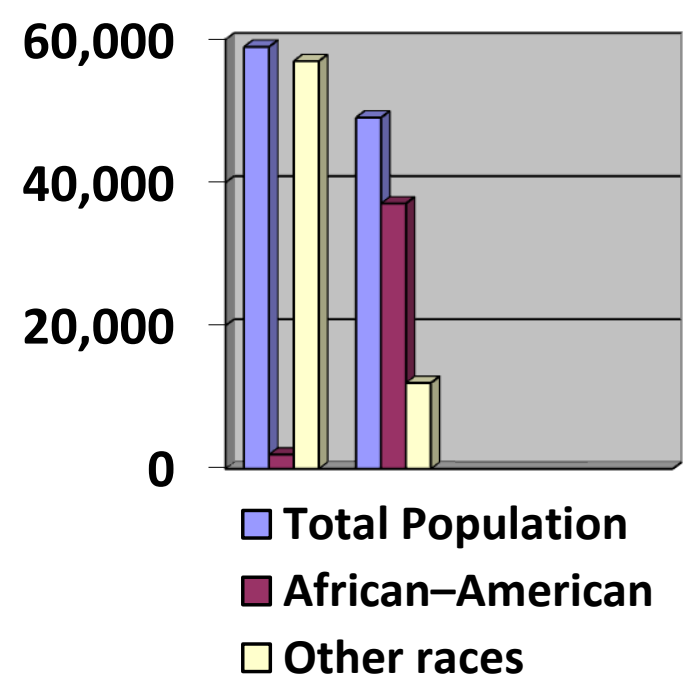

Figure 4. Total population of African American shown by the US Census. African American population percentage: Ames, IA: 3.4\%; Pine Bluff, AR: 75.6\%.

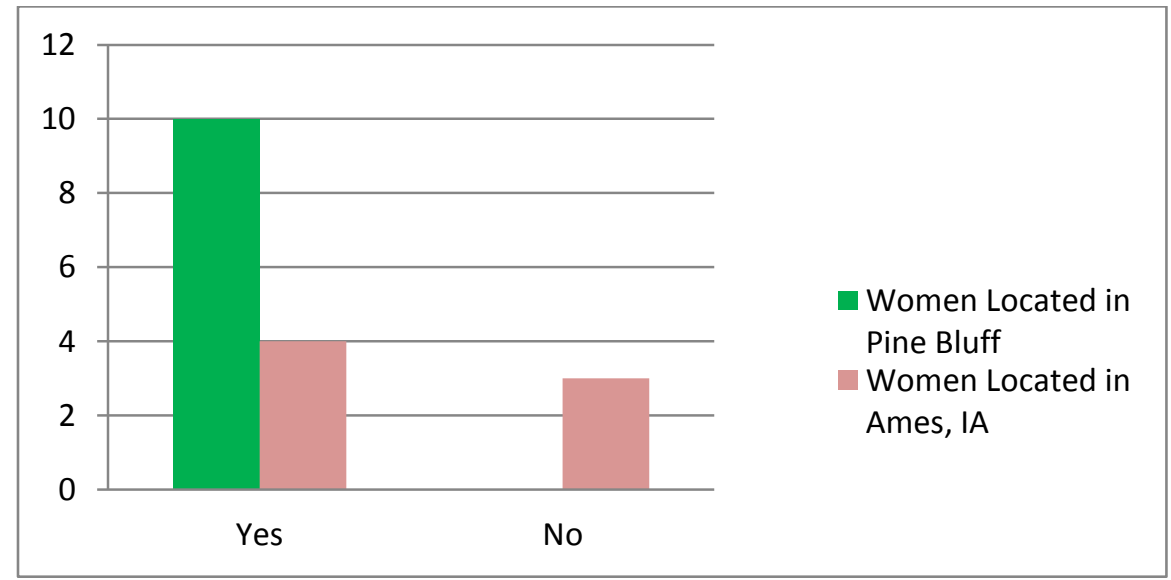

Figure 5. African American women's ability to find their correct foundation shade within the location where they lived. 
Many of the participants in Pine Bluff and Ames preferred to wear M.A.C. cosmetics. Participants from Pine Bluff wore M.A.C. cosmetics almost daily, and fewer wore M.A.C. cosmetics only on special occasions. The women from Pine Bluff stated that wearing M.A.C. cosmetics enhanced their facial features and gave them confidence. The women from Pine Bluff also expressed that M.A.C. cosmetics made them feel good about themselves, because M.A.C. catered to African American women who have oily, dry, or mixed skin types.

However, the participants who lived in Iowa were more likely to wear M.A.C. cosmetics only for special occasions rather than almost daily. Many of the women stated that they would prefer M.A.C. cosmetics over any other brand catering to African American women because of the high quality and long-lasting wearability (see Figure 6). Perhaps because more travel and effort was required to purchase M.A.C. in Iowa than in Pine Bluff, the Iowa residents may have used M.A.C. less and considered it something to save for special occasions. In addition, the women in Ames were university students on a campus known for
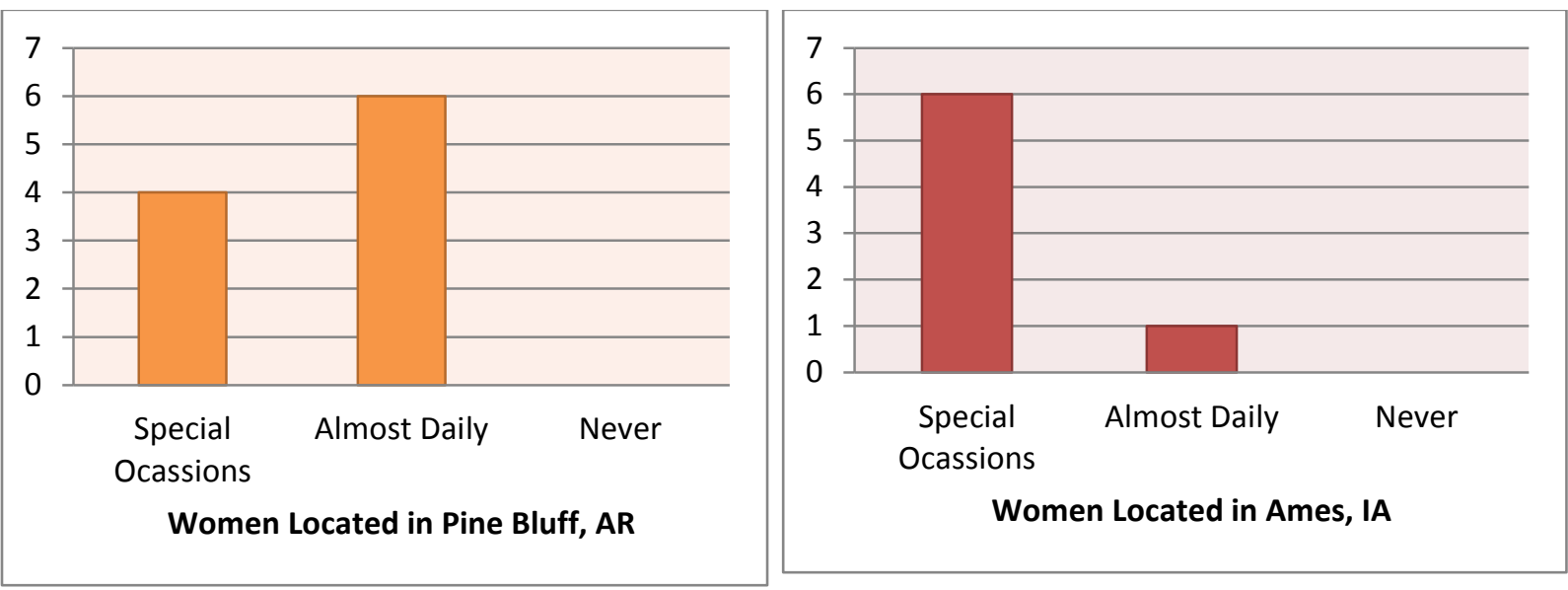

Figure 6. Frequency of M.A.C. makeup use of Pine Bluff, AR, and Ames, IA participants. 
its casualness of dress. The Pine Bluff women were more likely to be in the work world where they may need to present the self as a professional on a daily basis. Wearing cosmetics may be seen as a part of professional appearance.

\section{Theoretical Underpinnings}

A number of theories have been useful throughout this study. Social comparison theory (Festinger, 1954) contributed greatly to this study because it revealed that some of the participants engaged in downward social comparison when they did not have on cosmetics. Also, when the women interacted with someone who wore cosmetics, this made them feel less attractive. Furthermore, symbolic self-completion theory (Wicklund \& Gollwitzer, 1982) helps explain how the African American women define themselves when using and wearing cosmetics in their everyday lives. Cosmetics not only completed their look but helped them to feel confident in fulfilling hedonic demands of the female role.

Fredrickson and Roberts's (1997) self-objectification theory applied to this study to help understand why African American women are concerned about evaluation by others on the basis of their appearance. The women clearly had been socialized to objectify the self and frequently adopted an observer's perspective towards themselves.

Concepts of power (Weitz, 2001) help explain why African American women liked to look flawless and take control of their own personal beauty. The young adult African American women put forth an effort to put their idealized face forward and expressed a sense of empowerment in experimentation with and engrossment in cosmetics. At the same time, however, their adherence to cosmetics regimens indicated some entrapment in the norms of female hedonic role. There was great concern by many of the participants of the potential for negative surveillance by the "ubiquitous other" (Foucault, 1979). A few of the women were 
resistant (Weitz, 2001) to wearing cosmetics constantly but, nevertheless, enjoyed the use of them frequently, more as play and enjoyment rather than a necessity for achieving beauty.

In addition, several of the participants made negative comments about media

advertising of cosmetics and noticed the limited inclusion and overall exclusion of images of African American women who historically have been underrepresented in the media (HillCollins, 1990). Black feminist perspectives contribute an understanding of the women's valuations of cosmetics for African American women who desire to be included in cultural categories of beauty and to cultivate positive identities of African American women wearing cosmetics. In addition, Black feminism helps in the understanding of the symbolic importance of inclusion in the media by ethnic minority women who previously had been left out of cultural celebrations of beauty. African American women's evaluations of the media showed acceptance of the dominant cultural norms for female beauty by assimilating the media standard of beauty. While the access to desirable cosmetics helped the African American women have choice in participating in pursuit of beauty ideals, the constant and substantial use of cosmetics on the part of some of the women may indicate a docile relinquishing to cultural norms for objectification of women.

\section{Implications}

Understanding the context behind African American women's use of cosmetics products in relation to their attitudes and self-identity is an important step to understanding African American women's motivations behind their involvement in wearing cosmetics and the role that self-enhancement through cosmetics plays in their self-confidence and in their lives. Understanding why African American women participate in learning cosmetics 
techniques could be an important step in understanding why African American women construct their beauty around what the media portrays.

The results of this study should have practical benefits for the cosmetics industry to understand the importance of cosmetics for African American women. It is also important for cosmetic companies to understand African American consumers' development of wants and needs for the cosmetics products used. Brand marketing could be enhanced by developing high quality cosmetics products that will attract African American women and keep their loyalty and trust at an affordable price.

This study contributes to academic research because little to no research has explored African American women's use of cosmetics relating to their self-identity. Thus, this study was designed to fill a gap in the literature regarding the significance of African American women's concerns and beliefs about the use of cosmetics. The study explored African American women's experiences using cosmetic relating to their self-identity and the meanings behind their use of wearing cosmetics.

\section{Limitations}

With all studies there are limitations. One limitation to this study was the sample size, which was only 18 individuals. However, the participants were living in two different areas within the United States, providing evidence of the similarities and differences across regions. Having more participants and more in-depth interviews would increase the amount of rich data providing deeper understanding. The limited sample does not allow generalizability to the wider population.

There probably was an age effect in this study. What is valued and pursued in wearing cosmetic products relating to African America women's appearance, expressed by 
the participants of this study, may be different for women in other age ranges. For example, younger participants in their teens may evaluate the use of cosmetics product differently than did the participants of this study. It also would be interesting to expand the investigation to discover if there are different values placed on the use of cosmetics between younger African American adults and middle-aged and older African American women.

The use of in-person interviews may have caused a problem of honesty and openness for the participants, in particular, on their feelings related to cosmetics advertisements and their view on how African American women are portrayed. Furthermore, the potential lack of openness could have been enhanced by the interviewer. It was also possible that the interviewer influenced the responses of participants by possibly leading them to answer questions in a certain way because the interviewer uses cosmetics herself. Finally, some participants faced some difficulties with a time limit to answering the questions because of an electricity outage due to inclement weather in Pine Bluff, Arkansas. Therefore, these conditions may have affected the responses to some extent.

Finally, the sample may have been biased in that it is possible that only women who were fairly involved in cosmetics use volunteered to be interviewed. Perhaps other sampling approaches may have found some participants who did not use or did not like cosmetics.

\section{Future Research}

Many studies are needed to expand on what is known about the relationship among cosmetics, African American women, and their self-identity. A larger qualitative study would elicit more in-depth responses regarding African American women's attitudes toward cosmetics products in relation to their self-identity. A mixed-methods study, using a survey and interviews that ask African American women to give their views on how cosmetics make 
them feel and also explain why cosmetics are important in their lives, should be conducted. A mixed-methods approach could deepen understanding of consumer behavior toward cosmetics and allow for inclusion of large sample data. Another study that should be considered is one that develops a focus group of African American women to get their opinions, attitudes, and perspectives on cosmetics products and how using the products relate to their self-identity. Developing a focus group would be beneficial because several African American women can communicate as a group to express meaningful and honest information about cosmetics products relating to their self-identity.

Future investigations also should look at traditions other ethnic groups have involving wearing cosmetics. Large urban areas with high degree of ethnic diversity, such Washington, DC, and Atlanta, should be explored to get opinions of urban African American women on how the use of cosmetics is related to their self-identity. Also a generational study is needed to look at mother-daughter interactions in which the daughters model their mother's cosmetic use and are socialized to become consumers of cosmetics. 


\section{APPENDIX A. STUDY PARTICIPATION FLYER}

\section{African American women interested in the use of Cosmetics}

If you are an African American woman age 20-29 who likes to wear cosmetics or just wants to talk about how cosmetics make you feel... Let's have a talk.

I am conducting a research investigation on African American women's use of cosmetic products in relation to their attitudes and self-identity at lowa State University. The purpose of this research is to explore African American women's attitudes toward cosmetics, how women use cosmetics, and how use of the products is related to women's self-confidence and self-perception of appearance. The study will require one visit for a face-to face interview that will last no more than 1 hour.

Participation in this study is voluntary, and information about you will be kept completely confidential.

Each person who participates will receive a \$5 gift card.

If you are interested in this study you may contact LaPorchia Davis; please send an e-mail to Icdavis@iastate.edu for more information. 


\title{
APPENDIX B. INFORMED CONSENT DOCUMENTS
}

\author{
Iowa Informed Consent Document
}

Title of Study: African American women's use of cosmetic products in relation to their attitudes and self-identity

Investigators: LaPorchia Davis, Graduate Student

AESHM Department email: 1cdavis@iastate.edu or call (870-329-8506).

This is a research study. You are selected to participant in this study because you are an African American female student at Iowa State University. Please take your time in deciding if you would like to participate. Please feel free to ask questions at any time.

\section{INTRODUCTION}

This study is being conducted by a graduate student at Iowa State University to fulfill a Thesis for a master's program in Apparel, Merchandising, and Design. The purpose of this research is to explore African American women's attitudes toward cosmetics, how women use cosmetics, and how use of the products is related to women's self-confidence and self-perception of appearance. You are invited to participate in this study because you are an African American female individual between the ages of 20-29.

\section{DESCRIPTION OF PROCEDURES}

If you agree to participate in this study, your participation will last no more than one hour. The graduate student researcher will interview you about your experiences using cosmetics products and how they relate to your attitudes and self-identity as an African American woman. The one-onone interview will be conducted as your schedule allows. The interview sessions will be audiorecorded. The tapes will be transcribed by the researcher and will be erased following the transcription (within two months).

If you agree to be re-contacted, you may also be interviewed later for a check of accuracy of data and analysis. The second short interview will be audio recorded. The tapes will be transcribed by the researcher and will be erased following the transcription (within one month). The interview will be conducted as your schedule allows.

\section{RISKS}

The risks of this study are very minimal. While participating in this study you may experience possible discomfort at disclosing information during an interview.

\section{BENEFITS}

If you decide to participate in this study there will be no direct benefit to you. It is hoped that the information gained in this study will fill in a gap of understanding about African American women and use of cosmetic products. This information may lead to future studies identifying the cosmetic needs and preferences of other African American women.

\section{COSTS AND COMPENSATION}

Participants will be compensated for participating in this study with a \$5 Target gift card to thank them for taking the time to participate in the interview. No other compensation will be offered. 


\section{PARTICIPANT RIGHTS}

Your participation in this study is completely voluntary and you may refuse to participate or leave the study at any time. You may skip any questions you do not wish to answer and you may stop answering questions at any time. You may decide not to participate in the study or leave the study early for any reason without penalty.

\section{CONFIDENTIALITY}

Records identifying participants will be kept confidential and will not be made publicly available. To ensure confidentiality the following measures will be taken: The subjects will be assigned a code name which will be used on forms and in reports instead of their real names. Tapes of interviews will be recorded in a private room or via earphones, so that others besides the researcher, transcriber, and student's advisor cannot hear your voice. Only the researcher will know your name. Any identifying details obtained in the course of an interview will be generalized to protect confidentiality. All data gathered will be kept in a password coded computer file. In reports of the study, your name and any identifiable information will remain confidential.

\section{QUESTIONS OR PROBLEMS}

You are encouraged to ask questions at any time during this study.

- For further information about the study contact: LaPorchia Davis (researcher) by phone (870329-8506) or by e-mail at lcdavis@iastate.edu. Or contact the advisor for the project, Dr. Mary Lynn Damhorst, Apparel, Events, and Hospitality Management Department, 515-2949919, mldmhrst@iastate.edu.

- If you have any questions about the rights of research subjects or research-related injury, please contact the IRB Administrator, (515) 294-4566, IRB@iastate.edu, or Director, (515) 294-3115, Office for Responsible Research, Iowa State University, Ames, Iowa 50011.

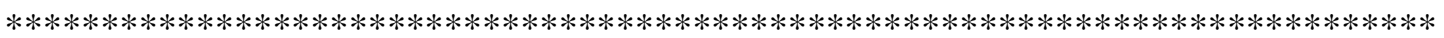

\section{PARTICIPANT SIGNATURE}

Your signature indicates that you voluntarily agree to participate in this study, that the study has been explained to you, that you have been given the time to read the document and that your questions have been satisfactorily answered. You will receive a copy of the written informed consent prior to your participation in the study.

Participant's Name (printed)

(Participant's Signature)

(Date) 


\section{$\underline{\text { Arkansas Informed Consent Document }}$}

Title of Study: African American women's use of cosmetic products in relation to their attitudes and self-identity

Investigators: LaPorchia Davis, Graduate Student

AESHM Department email: lcdavis@iastate.edu or call (870-329-8506).

This is a research study. You are selected to participant in this study because you are an African American female from the African American professional email listserve for Southeast Arkansas in the 20 to 29 age range. Please take your time in deciding if you would like to participate. Please feel free to ask questions at any time.

\section{INTRODUCTION}

This study is being conducted by a graduate student at Iowa State University to fulfill a Thesis for a master's program in Apparel, Merchandising, and Design. The purpose of this research is to explore African American women's attitudes toward cosmetics, how women use cosmetics, and how use of the products is related to women's self-confidence and self-perception of appearance. You are invited to participate in this study because you are an African American female individual between the ages of 20-29.

\section{DESCRIPTION OF PROCEDURES}

If you agree to participate in this study, your participation will last no more than one hour. The graduate student researcher will interview you about your experiences using cosmetics products and how they relate to your attitudes and self-identity as an African American woman. The one-onone interview will be conducted as your schedule allows. The interview sessions will be audiorecorded. The tapes will be transcribed by the researcher and will be erased following the transcription (within two months).

If you agree to be re-contacted, you may also be interviewed later for a check of accuracy of data and analysis. The second short interview will be audio recorded. The tapes will be transcribed by the researcher and will be erased following the transcription (within one month). The interview will be conducted as your schedule allows.

\section{RISKS}

The risks of this study are very minimal. While participating in this study you may experience possible discomfort at disclosing information during an interview.

\section{BENEFITS}

If you decide to participate in this study there will be no direct benefit to you. It is hoped that the information gained in this study will fill in a gap of understanding about African American women and use of cosmetic products. This information may lead to future studies identifying the cosmetic needs and preferences of other African American women.

\section{COSTS AND COMPENSATION}

Participants will be compensated for participating in this study with a \$5 Target gift card to thank them for taking the time to participate in the interview. No other compensation will be offered. 


\section{PARTICIPANT RIGHTS}

Your participation in this study is completely voluntary and you may refuse to participate or leave the study at any time. You may skip any questions you do not wish to answer and you may stop answering questions at any time. You may decide not to participate in the study or leave the study early for any reason without penalty.

\section{CONFIDENTIALITY}

Records identifying participants will be kept confidential and will not be made publicly available. To ensure confidentiality the following measures will be taken: The subjects will be assigned a code name which will be used on forms and in reports instead of their real names. Tapes of interviews will be recorded in a private room or via earphones, so that others besides the researcher, transcriber, and student's advisor cannot hear your voice. Only the researcher will know your name. Any identifying details obtained in the course of an interview will be generalized to protect confidentiality. All data gathered will be kept in a password coded computer file. In reports of the study, your name and any identifiable information will remain confidential.

\section{QUESTIONS OR PROBLEMS}

You are encouraged to ask questions at any time during this study.

- For further information about the study contact: LaPorchia Davis (researcher) by phone (870329-8506) or by e-mail at lcdavis@iastate.edu. Or contact the advisor for the project, Dr. Mary Lynn Damhorst, Apparel, Events, and Hospitality Management Department, 515-2949919, mldmhrst@iastate.edu.

- If you have any questions about the rights of research subjects or research-related injury, please contact the IRB Administrator, (515) 294-4566, IRB@iastate.edu, or Director, (515) 294-3115, Office for Responsible Research, Iowa State University, Ames, Iowa 50011.

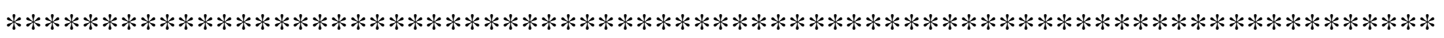

\section{PARTICIPANT SIGNATURE}

Your signature indicates that you voluntarily agree to participate in this study, that the study has been explained to you, that you have been given the time to read the document and that your questions have been satisfactorily answered. You will receive a copy of the written informed consent prior to your participation in the study.

Participant's Name (printed)

(Participant's Signature)

(Date) 


\section{APPENDIX C. DEMOGRAPHIC QUESTIONNAIRE}

Age

City and State where you reside

Major

Year in school (if applicable) (Check One)

Freshman

Sophomore

Junior

Senior

Masters

Doctoral

Highest level of education

Occupation or employment (if applicable)

Marital Status (Check One)

Single/Never Married

Single/Divorced

Married

Domestic Partnership (not married)

Widowed 


\section{APPENDIX D. INTERVIEW QUESTIONS}

Think back to when you first started wearing cosmetics; describe your first memory of selecting, buying and wearing cosmetics.

Tell me about your favorite cosmetic products? What types do you use? Do you have brand preferences?

Cosmetics may mean a lot to different women, but what do cosmetics mean to you?

What you define as cosmetics?

Can you tell me a little about your experiences shopping for cosmetics?

In what do cosmetics enhance your beauty?

Why do you wear cosmetics?

How often do you wear cosmetics?

For what situations do you wear cosmetics?

Do you use/apply cosmetics differently here in Ames from how you use them back home?

How do you find out about cosmetics and how to apply them? [probes: Do you look online, read magazines, learn from attendants at cosmetics counters, learn from friends/family, on Facebook, etc.]

Has there ever been a time when you looked at YouTube makeup tutorials for guidance to achieve a better look when putting on cosmetics?

Where do you shop for cosmetics? Do you have difficulties finding the brands and products that you need and like? Please explain, if so.

Do you like to wear cosmetics? Why or why not? What are your feelings about and attitudes towards cosmetics?

Do you feel that cosmetics are related in any way to your self-esteem of self-confidence? If so, in what ways?

Tell me about your feelings/attitudes on how cosmetics advertisements portray African American women? Would like to see any changes in cosmetics advertisements? 


\section{APPENDIX E. INSTITUTIONAL REVIEW BOARD APPROVAL}

\section{IOWA STATE UNIVERSITY \\ OWA OIATE UNIVERSITY
OF SCIENCE AND TECHNOLOGY}

$\begin{array}{ll}\text { Ames, lowa } 50011-2207 & 515294-4566 \\ \text { FAX } 515294-4267 & 1138 \text { Pear }\end{array}$

Date: $\quad 11 / 20 / 2012$

To: $\quad$ LaPorchia Chantell Davis

1221 Mayfield Dr Apt 205

Ames, IA 50014

From: $\quad$ Office for Responsible Research

Title: African American Women's Use of Cosmetic Products in Relation to Their Attitudes and Self-Identity

IRB ID: $\quad 12-570$

Study Review Date: 11/19/2012

\author{
Institutional Review Board \\ Office for Responsible Research \\ Vice President for Research \\ 1138 Pearson Hall
}
CC: Dr. Mary Lynn Damhorst
1068 LeBaron Hall

The project referenced above has been declared exempt from the requirements of the human subject protections regulations as described in 45 CFR 46.101(b) because it meets the following federal requirements for exemption:

- (2) Research involving the use of educational tests (cognitive, diagnostic, aptitude, achievement), survey or intenview procedures with adults or observation of public behavior where

- Information obtained is recorded in such a manner that human subjects cannot be identified directly or through identifiers linked to the subjects; or

- Any disclosure of the human subjects' responses outside the research could not reasonably place the subject at risk of criminal or civil liability or be damaging to their financial standing, employability, or reputation.

The determination of exemption means that:

- You do not need to submit an application for annual continuing review.

- You must carry out the research as described in the IRB application. Review by IRB staff is required prior to implementing modifications that may change the exempt status of the research. In general, review is required for any modifications to the research procedures (e.g., method of data collection, nature or scope of information to be collected, changes in confidentiality measures, etc.), modifications that result in the inclusion of participants from vulnerable populations, and/or any change that may increase the risk or discomfort to participants. Changes to key personnel must also be approved. The purpose of review is to determine if the project still meets the federal criteria for exemption.

Non-exempt research is subject to many regulatory requirements that must be addressed prior to implementation of the study. Conducting non-exempt research without IRB review and approval may constitute non-compliance with federal regulations and/or academic misconduct according to ISU policy.

Detailed information about requirements for submission of modifications can be found on the Exempt Study Modification Form. A Personnel Change Form may be submitted when the only modification involves changes in study staff. If it is determined that exemption is no longer warranted, then an Application for Approval of Research Involving Humans Form will need to be submitted and approved before proceeding with data collection. 


\section{REFERENCES}

American Society for Aesthetic Plastic Surgery (ASAPS). (n.d.). Understanding women's complicated relationship to the mirror. Facial Aesthetic Surgery. Retrieved from the ASAPS website: http://www.surgery.org/media/news-releases/understandingwomens-complicated-relationship-to-the-mirror

Beauty whitewashed: How White ideals exclude women of color. (2011, February 1). Beauty Redefined. Retrieved from http://www.beautyredefined.net /beauty-whitewashedhow-white-ideals-exclude-women-of-color/

Beausoleil, N. (1992). Makeup in everyday life: An inquiry into the practices of urban American women of diverse backgrounds. In N. Sault (Ed.), Many mirrors: Body image and social relations (pp. 33-57). New Brunswick, NJ: Rutgers University

Bloch, P. H., \& Richins, M. L. (1992). You look "mahvelous": The pursuit of beauty and the marketing concept. Psychology and Marketing, 9(1), 3-15.

Bordo, S. R. (1989). The body and the reproduction of femininity: A feminist appropriation of Foucault. In A. M. Jaggar \& S. R. Bordo (Eds.), Gender/body/knowledge (pp.1333). New Brunswick, NJ: Rutgers University Press.

Botta, R. (2000). The mirror of television: A comparison of Black and White adolescents' body image. Journal of Communication, 50(3), 144-159.

Buunk, B. P., \& Mussweiler, T. (2001). New directions in social comparison research. European Journal of Social Psychology, 31, 467-475.

Cash, T. F., \& Pruzinsky, T. (Eds.). (2002). Body images: A handbook of theory, research, and clinical practice. New York, NY: Guilford Press.

Cash, T. F., Rissi, J., \& Chapman, R. (1985). Not just another pretty face: Sex roles, locus of control, and cosmetics use. Personality and Social Psychology Bulletin, 11(3), 246257. 
Charon, J. M. (1985). Symbolic interactionism (2nd ed.). Englewood Cliffs, NJ: PrenticeHall.

Chaudhri, S. K., \& Jain, N. K., (2009). History of cosmetics. Asian Journal of Pharmaceutics, 3, 164-167.

Copeland, S., Grodnitzky, S., \& Cowen, D. (2002). Beauty pageants: Private benefit worth watching. Retrieved from http://www.irs.gov/pub//irs-tege/eotopicb02.pdf

Davies, S. (1995). Leaps of faith: Shifting currents in critical sociology of education. American Journal of Sociology, 100, 1448-1478.

Davis, K. (1995). Reshaping the female body. New York, NY: Routledge.

DeBord, K. (1997). Emotional well-being: Women's self-esteem. Columbia, MO: University Extension, University of Missouri. Retrieved from http://extension.missouri.edu /explorepdf/hesguide/humanrel/gh6652.pdf

Denzin, N., \& Lincoln, Y. (1998). Introduction: Entering the field of qualitative research. In N. K. Denzin \& Y. S. Lincoln (Eds.), The landscape of qualitative research: Theories and issues (pp. 1-40). Thousand Oaks, CA: Sage Publications.

Dhar, R., \& Wertenbroch, K. (2000). Consumer choice between hedonic and utilitarian goods. Journal of Marketing Research, 37(1), 60-71.

Dion, K., Breached, E., \& Walter, E. (1972). What is beautiful is good. Journal of Personality and Social Psychology, 24, 285-290.

Draelos, Z. D. (2001). Overview: Cosmetics and the art of adornment. Dermatologic Therapy, 14, 175-177.

Duke, L. (2002). Get real!: Cultural relevance and resistance to the mediated feminine ideal. Psychology \& Marketing, 19(2), 211-233. 
Esterberg, K. G. (2002). Qualitative methods in social research. New York, NY: McGraw Hill.

Etcoff, N., Orbach, S., Scott, J., \& D'Agostino, H. (2004). The real truth about beauty: A global report. Unilever. Retrieved from http://www.clubofamsterdam.com /contentarticles/52\%20Beauty/dove_white_paper_final.pdf

Falconer, J. W., \& Neville, H. A. (2000). African American college women's body image: An examination of body mass, African self- consciousness, and skin color satisfaction. Psychology of Women Quarterly, 24(3), 236-243.

Festinger, L. (1954). A theory of social comparison processes. Human Relations, 7, 117-140.

Foucault, M. (1979). Discipline and punish: The birth of the prison. New York, NY: Vintage.

Fredrickson, B. L., \& Roberts, T. (1997). Objectification theory. Psychology of Women Quarterly, 21(2), 173.

Freedman, R. (1986). Beauty bound. Lexington, MA: D.C. Heath.

Goffman, E. (1959). The presentation of self in everyday life. Garden City, NY: Doubleday Anchor Books.

Gottfredson, L. S. (1985). Role of self-concept in vocational theory. Journal of Counseling Psychology, 32, 159-162.

Graham, J. A. (1985). Overview of psychology of cosmetics. In J. A. Graham \& A.M. Kligman (Eds.), The psychology of cosmetic treatments (pp. 26-36). New York, NY: Praeger.

Guy, A., \& Banim, M. (2000). Personal collections: Women's clothing use and identity. Journal of Gender Studies, 9(3), 313-327. 
Guegunen, N., \& Jacob, C. (2010). Enhanced female attractiveness with use of cosmetics and male tipping behavior in restaurants. Journal of Cosmetic Science, 62, 283-290.

Hamermesh, D. S., \& Biddle, J. E. (1994). Beauty and the labor market. American Economic Revenue, 84, 1174-1194.

Hill, M. E. (2002). Skin color and the perception of attractiveness among African Americans: Does gender make a difference? Social Psychology Quarterly, 65(1), 77-91.

Hill-Collins, P. (1990). Black feminist thought: Knowledge, consciousness and the politics of empowerment. Boston, MA: Unwin Hyman.

Irving, L. M. (1990). Mirror images: Effects of the standard of beauty on the self and bodyesteem of women exhibiting varying levels of bulimic symptoms. Journal of Social and Clinical Psychology, 9, 230-242.

Jones, A. M., \& Buckingham, J. T. (2005). Self-esteem as a moderator of the effect of social comparison on women's body image. Journal of Social \& Clinical Psychology, 24(8), 1164-1187.

Jones, C., \& Shorter-Gooden, K. (2003). Shifting: The double lives of Black women in America. New York, NY: HarperCollins.

Kaiser, S. B. (1997). The social psychology of clothing: Symbolic appearance in context. (2nd ed.). New York, NY: Fairchild.

Kelson, T. R., Kearney-Cooke, A., \& Lansky, L. M. (1990). Body image and body beautification among female college students. Perceptual and Motor Skills, 71, 281289.

Krolokke, C., \& Sorensen, A. S. (2006). Gender communication theories and analyses: From silence to performance. Thousand Oaks, CA: Sage.

La Belle, J. (1988). Herself beheld: The literature of the looking glass. Ithaca, NY: Cornell University Press. 
Lee, J., \& Johnson, K. K. P. (2009). Factors related to engagement in risky appearance management behaviors. Clothing and Textile Research Journal, 27(3), 163-178.

Lee, V. (2012, February 15). Annie Minerva Turnbo Malone: Beauty pioneer. Examiner.com. Retrieved from http://www.examiner.com/article/annie-minerva-turnbo-malonebeauty-pioneer

Lerner, R. M., Karabenick, S. A., \& Stuart, J. L. (1973). Relations among physical attractiveness, body attitudes, and self-concept in male and female college students. Journal of Psychology, 85(1), 119-129.

Life in the plastic. (2005). In M. L. Damhorst, K. A. Miller-Spillman, \& S. O. Michelman (Eds.), The meanings of dress (2nd ed.; pp. 166-169). New York: Fairchild.

Ligget, A. (2012). Research shows college-aged women buy cosmetics strive for physical beauty more during recession. College Times. Retrieved from http://www.ecollegetimes.com/student-life/research-shows-college-aged-women-buycosmetics-strive-for-physical-beauty-more-during-recession-1.2746846

Lombard, M., Snyder-Duch, J., \& Campanella Bracken, C. (2002). Content analysis in mass communication: Assessment and reporting of intercoder reliability. Human Communication Research, 28(4), 597-604.

Lucas, A. (1930). Cosmetics, perfumes and incense in Ancient Egypt. Journal of Egyptian Archaeology, 16(1), 41-53.

Lynch, M. S. (2007). An exploration of the relationship between ideal( $s$ ) of female beauty, self-perception(s) of female beauty, and self esteem in women (Unpublished master's thesis). Smith College School for Social Work, Northampton, MA.

M.A.C. AIDS Fund. (n.d). MAC AIDS fund. Retrieved from the MAC AIDS Fund website: http://www.macaidsfund.org/\#/glam/campaignhistory 
Marlowe, C. W., Schneider, S. L., \& Nelson, C. E. (1996). Gender and attractiveness biases in hiring decisions: Are more experienced managers less biased? Journal of Applied Psychology, 81, 11-21.

Martin, C. L., \& Baugh, E. J. (2011). Minority women, media, and body image. Gainesville: University of Florida, IFAS Extension.

McAlexander, J. H., \& Schouten, J. (1989). Hairstyle changes as transition makers. Sociology and Social Research, 74(1), 58-62.

Mead, G. H. (1934). Mind, self and society from the standpoint of a social behaviorist. (C. W. Morris, Ed.). Chicago, IL: University of Chicago.

Body image: Advertising. (n.d.) Retrieved from the Media Awareness website: http://mediasmarts.ca/body-image/body-image-advertising-and-magazines

MediaSmarts. (n.d.). Body image: Toys. Retrieved from the MediaSmarts website: www.mediasmarts.ca/body-image/body-image-toys

Miller, L. C., \& Cox, C. L. (1982). For appearances' sake: Public self-consciousness and makeup use. Personality and Social Psychology Bulletin, 8, 748-751.

Monro, F., \& Huon, G. (2005). Media-portrayed idealized images, body shame, and appearance anxiety. International Journal of Eating Disorders, 38(1), 85-90.

Nash, F., Fieldman, T., Hussey, J. T., Leveque, L., \& Pineau, P. (2006). Cosmetics: They influence more than Caucasian female facial attractiveness. Journal Applied Social Psychology, 36, 493-504.

Pajares, F., \& Schunk, D. H. (2001). Self-beliefs and school success: Self-efficacy, selfconcept, and school achievement. In R. J. Riding \& S. G. Rayner (Eds.), International perspectives on individual differences (Vol. 2, pp. 239-266). Westport, CT: Ablex. 
Parker, S., Nichter, M., Vuckovic, N., Sims, C., \& Ritenbaugh, C. (1995). Body image and weight concerns among African American and White adolescent females: Difference that makes a difference. Human Organization, 54(2), 1-8.

Pompper, D., \& Koenig, J. (2004). Cross-cultural generational perceptions of ideal body image: Hispanic women and magazine standards. Journalism \& Mass Communication Quarterly, 81(1), 89-107

Poran, M. A. (2002). Denying diversity: Perceptions of beauty and social comparison processes among Latina, Black, and White women. Sex Roles: A Journal of Research, $47(1-2), 65-81$.

Poran, M.A. (2006). The politics of protection: Body image, social pressures and the misrepresentation of young black women. Springer Science, 55, 739-755.

Renfrew Center Foundation for Eating Disorders. (2012). New survey results indicate there's more to makeup use than meets the eye. Retrieved from Renfrew Center website: http://renfrewcenter.com/sites/default/files/press_release_pdfs/Barefaced\%20and\%20 Beautiful\%20Release\%20-\%20FINAL.pdf

Robertson, J., Fieldman, G., \& Hussey, T. (2008). “Who wears cosmetics?” Individual differences and their relationship with cosmetic usage. Retrieved from http://bucksuk.academia.edu//JuliaRobertson/Papers/175233/_Who_wears_Comestics_Individual Differences_and their_Relationship_with_Cosmetic_Usage

Rosenberg, M., \& Pearlin, L. I. (1978). Social class and self-esteem among children and adults. American Journal of Sociology, 84(1), 53-77.

Saint Louis, C. (2011, October 12). Up the career ladder, lipstick in hand. The New York Times. Retrieved from http://www.nytimes.com/2011/10/13/fashion/makeup-makeswomen-appear-more-competent-study.html? $\mathrm{r}=1$

Sampey, K. (2012). African Americans show more "love" to brands than Caucasians. NewMediaMetrics. Retrieved from http://finance.yahoo.com/news/african-americansshow-more-love-140000467.html 
Sanders, E. A. (2011). Female slave narratives and appearance: Assimliation, experience, and escape. Clothing and Textiles Research Journal, 29(4), 267-283.

Schmitt, D. P., \& Allik, J. (2005). Simultaneous administration of the Rosenberg Self-Esteem Scale in 53 nations: Exploring the universal and culture-specific features of global self-esteem. Journal of Personality and Social Psychology, 89, 623-642.

Scott, J. C. (1990). Domination and the arts of resistance: Hidden transcripts. New Haven, CT: Yale University Press.

Scott, S. (2007). Influence of cosmetics on the confidence of college women: An exploratory study. (Unpublished master's thesis). Hanover College, Hanover, IN.

Sinclair, S. L. (2006). Object lessons: A theoretical and empirical study of objected body consciousness in women. Journal of Mental Health Counseling, 28(1), 48-68.

Smith, S. (2009). Essence panel explores beauty purchasing. Women's Wear Daily. Retrieved from http://www.wwd.com/beauty-industry-news/marketing-trends/essence-panelexplores-beauty-purchasing-2139829

Stombler, M., \& Padavic, I. (1997). Sister acts: Resisting men's domination in Black and White fraternity little sister programs. Social Problems, 44, 257-275.

Stone, G. P. (1965). Appearance and the self. In M. E. Roach \& J. B. Eicher (Eds.), Dress, adornment, and the social order (pp. 216-245). New York, NY: Wiley \& Sons.

Strauss, A., \& Corbin, J. (1990). Basics of qualitative research: Grounded theory procedures and techniques $\left(2^{\text {nd }}\right.$ ed.). Thousand Oaks, CA: Sage.

Sun, F. (2012). Sephora and Pantone's new foundation matching solution. Time Magazine. Retrieved from http://www.time.com/time/specials/packages/article /0,28804,2108496_2113332_2120345,00.html.

Swain, F. O. (2012). Negotiating beauty ideals: Perceptions of beauty among black female university students (Unpublished Master's thesis). Georgia State University, Atlanta. 
Tahmincioglu, E. (2012, May). For women in the workplace, it's still about the looks not deeds. Life Inc. Retrieved from http://lifeinc.today.msnbc.msn.com/_news/2012/05 /15/11698778-for-women-in-the-workplace-its-still-about-looks-not-deeds?lite

Tajfel, H., \& Turner, J.C. (1979). An integrative theory of intergroup conflict. In W.G. Austin \& S. Worchel (Eds.), The social psychology of intergroup relations (pp. 3347). Monterey, CA: Brooks-Cole.

Taylor, U. (1998). The historical evolution of Black feminist theory and praxis. Journal of Black Studies, 29(2), 234-253.

Tesser, A., \& Campbell, J. (1984). Friendship choice and performance: Self-evaluation maintenance in children. Journal of Personality and Social Psychology. 46, 561-574.

Tiggemann, M., \& McGill, B. (2004). The role of social comparison in the effect of magazine advertisements on women's mood and body dissatisfaction. Journal of Social \& Clinical Psychology, 23(1), 23-44.

Trampe, D., Stapel, D. A., \& Siero, F. W. (2007). On models and vases: Body dissatisfaction and proneness to social comparison effects. Journal of Personality and Social Psychology, 92(1), 106-118.

Tseelon, E. (2012). Fashion and the orders of masking. Critical Studies in Fashion \& Beauty, 3(1\&2), 3-9.

Turner, S. L., Hamilton, H., Jacobs, M., Angood, L. M., \& Dwyer, D. H. (1997). The influence of fashion magazines on the body image satisfaction of college women: An exploratory analysis. Adolescence, 32(127), 603-614.

Tyner, K. E. (2008). Cosmetic technologies of the body: An exploration of self and identity through the consumption of nonsurgical cosmetic procedures (Unpublished doctoral dissertation). Iowa State University, Ames. 
Wakefield, K. L., \& Inman, J. (2003) Situational price sensitivity: The role of consumption occasion, social context and income. Journal of Retailing, 79(4), 199-212.

Weitz, R. (2001). Women and their hair: Seeking power through resistance and accommodation. Gender \& Society, 15(5), 667-686.

Wells, F. V., \& Lubowe, I. I. (1964). Cosmetics and the skin. New York, NY: Reinhold.

Wicklund, R. A., \& Gollwitzer, P. M. (1982). Symbolic self-completion. Hillsdale, NJ: Erlbaum.

Willet, J. (2010). The American beauty industry encyclopedia. Retrieved from http://books .google.com/books?id=CljLw4sH2DMC\&pg=PA11\&lpg=PP1\&output=html_text

Willis, T. A. (1987). Downward comparison as a coping mechanism. In C.R. Snyder \& C. Ford (Eds), Coping with negative life events: Clinical and social psychological perspectives (pp.243-267). San Diego, CA: Academic Press.

Wolf, N. (1991). The beauty myth: How images of beauty are used against women. NewYork, NY: William Morrow.

Wood, J. A. (1989). Theory and research concerning social comparison of personal attributes. Psychological Bulletin, 106(2), 231-248. 